\title{
Chemistry-climate model simulations of twenty-first century stratospheric climate and circulation changes
}

Article

Published Version

Butchart, N., Cionni, I., Eyring, V., Shepherd, T. G., Waugh, D. W., Akiyoshi, H., Austin, J., Brühl, C., Chipperfield, M. P., Cordero, E., Dameris, M., Deckery, R., Dhomse, S., Frith, S. M., Garcia, R. R., Gettelman, A., Giorgetta, M. A., Kinnison, D. E., Li, F., Mancini, E., McLandress, C., Pawson, S., Pitari, G., Plummer, D. A., Rozanov, E., Sassi, F., Scinocca, J. F., Shibata, K., Steil, B. and Tian, W. (2010) Chemistry-climate model simulations of twenty-first century stratospheric climate and circulation changes. Journal of Climate, 23 (20). pp. 53495374. ISSN 1520-0442 doi: https://doi.org/10.1175/2010JCLI3404.1 Available at https://centaur.reading.ac.uk/31612/

It is advisable to refer to the publisher's version if you intend to cite from the work. See Guidance on citing.

To link to this article DOI: http://dx.doi.org/10.1175/2010JCLI3404.1

Publisher: American Meteorological Society

All outputs in CentAUR are protected by Intellectual Property Rights law, 
including copyright law. Copyright and IPR is retained by the creators or other copyright holders. Terms and conditions for use of this material are defined in the End User Agreement.

\section{www.reading.ac.uk/centaur}

\section{CentAUR}

Central Archive at the University of Reading

Reading's research outputs online 


\title{
Chemistry-Climate Model Simulations of Twenty-First Century Stratospheric Climate and Circulation Changes
}

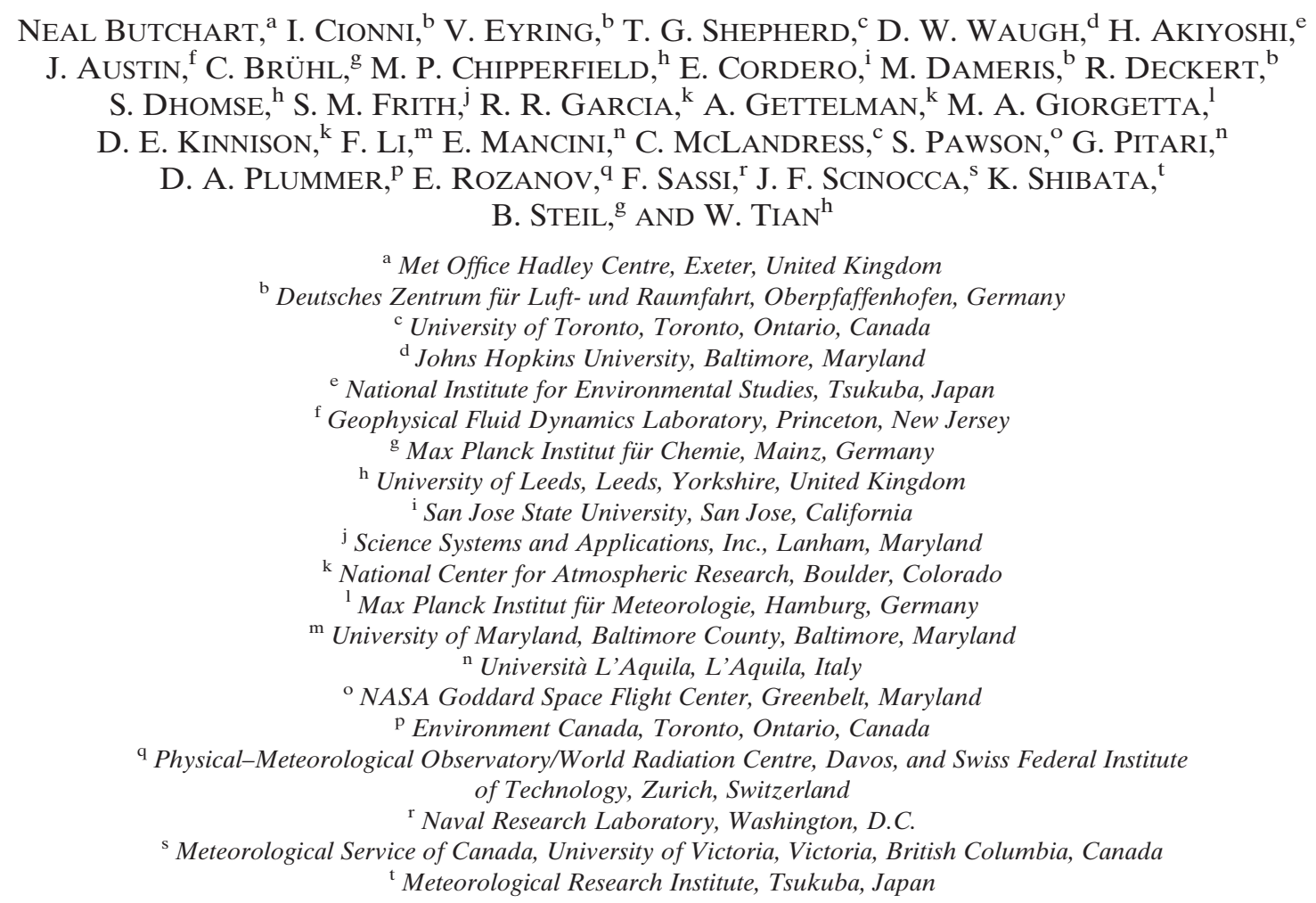

(Manuscript received 31 August 2009, in final form 23 February 2010)

\begin{abstract}
The response of stratospheric climate and circulation to increasing amounts of greenhouse gases (GHGs) and ozone recovery in the twenty-first century is analyzed in simulations of 11 chemistry-climate models using near-identical forcings and experimental setup. In addition to an overall global cooling of the stratosphere in the simulations $\left(0.59 \pm 0.07 \mathrm{~K} \mathrm{decade} \mathrm{e}^{-1}\right.$ at $\left.10 \mathrm{hPa}\right)$, ozone recovery causes a warming of the Southern Hemisphere polar lower stratosphere in summer with enhanced cooling above. The rate of warming correlates with the rate of ozone recovery projected by the models and, on average, changes from 0.8 to $0.48 \mathrm{~K} \mathrm{decade}^{-1}$ at $100 \mathrm{hPa}$ as the rate of recovery declines from the first to the second half of the century. In the winter northern polar lower stratosphere the increased radiative cooling from the growing abundance of GHGs is, in most models, balanced by adiabatic warming from stronger polar downwelling. In the Antarctic lower stratosphere the models simulate an increase in low temperature extremes required for polar stratospheric cloud (PSC) formation, but the positive trend is decreasing over the twenty-first century in all models. In the Arctic, none of the models simulates a statistically significant increase in Arctic PSCs throughout the twentyfirst century. The subtropical jets accelerate in response to climate change and the ozone recovery produces a westward acceleration of the lower-stratospheric wind over the Antarctic during summer, though this response is sensitive to the rate of recovery projected by the models. There is a strengthening of the Brewer-Dobson
\end{abstract}

Corresponding author address: Neal Butchart, Met Office, Hadley Centre, FitzRoy Road, Exeter, Devon, EX1 3PB, United Kingdom.

E-mail: neal.butchart@metoffice.gov.uk 
circulation throughout the depth of the stratosphere, which reduces the mean age of air nearly everywhere at a rate of about $0.05 \mathrm{yr} \mathrm{decade}^{-1}$ in those models with this diagnostic. On average, the annual mean tropical upwelling in the lower stratosphere $(\sim 70 \mathrm{hPa})$ increases by almost $2 \%$ decade $^{-1}$, with $59 \%$ of this trend forced by the parameterized orographic gravity wave drag in the models. This is a consequence of the eastward acceleration of the subtropical jets, which increases the upward flux of (parameterized) momentum reaching the lower stratosphere in these latitudes.

\section{Introduction}

This paper is a study of the predicted stratospheric climate and circulation changes in a multimodel ensemble of chemistry-climate model (CCM) simulations of the twenty-first century. The simulations were carried out in support of the 2006 World Meteorological Organization (WMO)/United Nations Environment Programme (UNEP) Scientific Assessment of Ozone Depletion (WMO 2007). Eyring et al. (2006) evaluated the ability of the CCMs used in these simulations to reproduce the behavior of temperature, trace species, and ozone in the recent past, and they concluded that despite a huge range of skills in representing the different processes assessed, there was sufficient agreement between the majority of the CCMs and observations that some confidence could be placed in their predictions. Consequently, Eyring et al. (2007) were able to analyze projections of the ozone recovery in the simulations of the twenty-first century, but, aside from noting that there was the expected cooling of the middle atmosphere, no detailed analysis was carried out of the dynamical changes in the simulations. This study therefore complements that of Eyring et al. (2007).

Climate and circulation changes in the stratosphere can have a major influence on the ozone layer in several ways. Because chemical reactions are temperature dependent, a systematic cooling of the upper stratosphere can slow the rate of photochemical ozone destruction in that region. On the other hand, a cooling of the wintertime polar lower stratosphere can increase the occurrence of polar stratospheric clouds (PSCs) and enhance halogen-induced ozone loss in those regions. Circulation changes can have an impact on the transport of ozonedepleting substances (ODSs) into the stratosphere and on their lifetimes (Butchart and Scaife 2001), in addition to affecting temperatures through adiabatic processes. Changes in both transport and temperatures will affect the water vapor input into the stratosphere, while changes in dynamical processes will affect the transport of ozone within the stratosphere and across the tropical tropopause. Therefore, even in the absence of ODSs, climate change can alter the stratospheric ozone distribution. In addition there is now evidence that stratospheric climate and circulation changes are a factor in the evolution of the surface climate and its variability (e.g., Perlwitz and Harnik 2003; Scaife et al. 2005; Baldwin et al. 2007).

The purpose of this study is to analyze the predicted stratospheric climate change obtained from 11 of the CCMs used for the ozone predictions in WMO (2007). One aim is to establish which aspects of stratospheric climate and circulation change are robust, that is, model independent. Although all of the models are CCMs, the analysis presented in this paper is based only on diagnostics that are obtained from the variables (e.g., winds and temperature) used in the underlying general circulation models (GCMs), with the exception of the PSC area, the total ozone, and an age-of-air tracer, which, when available, is used to diagnose circulation changes. In contrast to previous comparisons of stratospheric climate predictions, the CCM simulations used here are all transient simulations and have almost identical experimental setups and forcings, though there are differences in the forcings from the predicted ozone (e.g., Eyring et al. 2007) and other radiatively active gases resulting from feedbacks from the coupled chemistry in these models. The analyses update or extend the few other published intercomparisons of stratospheric predictions, including the PSC diagnostics as assessed in Austin et al. (2003), the temperature changes discussed in Eyring et al. (2007), and the changes in tropical upwelling considered by Butchart et al. (2006).

A brief description of the models and simulations is presented in section 2. Predicted changes in the stratospheric climate (zonal mean temperature, PSC occurrence, and eastward wind) can be found in section 3 . Section 4 contains an analysis of the circulation changes with the downward control principle of Haynes et al. (1991) used to diagnose the contributions to these changes from resolved and parameterized subgrid-scale waves. A summary and concluding remarks appear in section 5.

\section{Models and simulations}

Results have been obtained from 11 CCMs that performed twenty-first century reference/sensitivity simulations for WMO (2007). The resolution and vertical domain of the models are given in Table 1 along with the representation of subgrid-scale momentum deposition in the middle atmosphere from nonorographic gravity waves. All of the models apart from the University of 
TABLE 1. Resolution, vertical domain, and nonorographic gravity wave drag parameterizations used in the models. The models are listed alphabetically by name. For gridpoint models the horizontal resolution is given as the latitude $\times$ longitude grid spacing $\left({ }^{\circ}\right)$. For spectral models the horizontal resolution is given as the triangular truncation of the spectral domain, with the equivalent gridpoint resolution in brackets.

\begin{tabular}{|c|c|c|}
\hline Model & Horizontal resolution, No. of levels, top level & Nonorographic GWD \\
\hline AMTRAC & $\begin{array}{l}2^{\circ} \times 2.5^{\circ} \\
\quad 48 \mathrm{~L}, 0.0017 \mathrm{hPa}\end{array}$ & Alexander and Dunkerton (1999) \\
\hline CCSR/NIES & $\begin{array}{l}\mathrm{T} 42\left(2.8^{\circ} \times 2.8^{\circ}\right) \\
\quad 34 \mathrm{~L}, 0.01 \mathrm{hPa}\end{array}$ & Hines (1997) \\
\hline CMAM & $\begin{array}{r}\mathrm{T} 32\left(3.75^{\circ} \times 3.75^{\circ}\right) \\
71 \mathrm{~L}, 0.0006 \mathrm{hPa}\end{array}$ & Scinocca (2003) \\
\hline E39C & $\begin{array}{l}\mathrm{T} 30\left(3.75^{\circ} \times 3.75^{\circ}\right) \\
\quad 39 \mathrm{~L}, 10 \mathrm{hPa}\end{array}$ & $\begin{array}{l}\text { Enhanced horizontal diffusion } \\
\text { in the two uppermost layers }\end{array}$ \\
\hline GEOS CCM & $\begin{array}{l}2^{\circ} \times 2.5^{\circ} \\
55 \mathrm{~L}, 0.01 \mathrm{hPa}\end{array}$ & $\begin{array}{l}\text { Based on Lindzen (1981), Holton (1982), } \\
\text { and Garcia and Solomon (1985) }\end{array}$ \\
\hline MAECHAM4CHEM & $\begin{array}{l}\mathrm{T} 30\left(3.75^{\circ} \times 3.75^{\circ}\right) \\
\quad 39 \mathrm{~L}, 0.01 \mathrm{hPa}\end{array}$ & Hines (1997) \\
\hline MRI & $\begin{array}{c}\mathrm{T} 42\left(2.8^{\circ} \times 2.8^{\circ}\right) \\
\quad 68 \mathrm{~L}, 0.01 \mathrm{hPa}\end{array}$ & Hines (1997) \\
\hline SOCOL & $\begin{array}{l}\mathrm{T} 30\left(3.75^{\circ} \times 3.75^{\circ}\right) \\
\quad 39 \mathrm{~L}, 0.01 \mathrm{hPa}\end{array}$ & Hines (1997) \\
\hline ULAQ & $\begin{array}{l}10^{\circ} \times 22.5^{\circ} \\
\quad 26 \mathrm{~L}, 0.04 \mathrm{hPa}\end{array}$ & Rayleigh friction (Smith and Lyjak 1985) \\
\hline UMSLIMCAT & $\begin{array}{l}2.5^{\circ} \times 3.75^{\circ} \\
\quad 64 \mathrm{~L}, 0.01 \mathrm{hPa}\end{array}$ & $\begin{array}{l}\text { Warner and McIntyre (1996) } \\
\text { and Scaife et al. (2002) }\end{array}$ \\
\hline WACCM (version 3) & $\begin{array}{l}4^{\circ} \times 5^{\circ} \\
\quad 66 \mathrm{~L}, 4.5 \times 10^{-6} \mathrm{hPa}\end{array}$ & $\begin{array}{l}\text { Based on Lindzen (1981), Holton (1982), } \\
\text { and Garcia and Solomon (1985) }\end{array}$ \\
\hline
\end{tabular}

L'Aquila (ULAQ) model include a parameterization of orographic gravity wave drag (GWD), though in the Meteorological Research Institute (MRI) model the parameterized orographic waves do not propagate into the stratosphere and in the Atmospheric Model with Transport and Chemistry (AMTRAC) the drag from these waves is set to zero above $42 \mathrm{hPa}$.

Because the models are CCMs they include both gasphase chemistry and heterogeneous chemistry on aerosols and PSCs, though different PSC, dehydration, and denitrification schemes are used. Except for the Canadian Middle Atmosphere Model (CMAM), which did not include a parameterization for nitric acid trihydrate (NAT) PSCs (see Hitchcock et al. 2009, p. 484b), all of the models calculate solid PSCs based on simulated temperature, nitric acid, and water vapor concentrations using the Hanson and Mauersberger (1988) formulas. All of the models include the calculation of liquid sulfate aerosols, but again they use different schemes. In addition, most models [i.e., Center for Climate System Research (CCSR)/National Institute of Environmental Studies (NIES), CMAM, Goddard Earth Observing System (GEOS) CCM, Unified Model Single Layer Isentropic Model of Chemistry And Transport (UMSLIMCAT), and Whole-Atmosphere Community Climate Model (WACCM)] calculate liquid aerosols from a supercooled ternary solution (STS) using approaches similar to, for example, Carslaw et al. (1995) or Considine et al. (2000). Further details of the models can be found in Eyring et al. (2006, their Table 1 and references therein).

The reference (REF2) and sensitivity (SCN2) simulations broadly follow the specifications given by Eyring et al. (2005). Briefly, these are

- surface concentrations of greenhouse gases (GHGs) follow the Intergovernmental Panel on Climate Change (IPCC) Special Report on Emissions (SRES) GHG scenario A1B (medium; see Nakicenovic and Swart 2000);

- sea surface temperatures and sea ice distributions (hereafter referred to as SSTs) are, if available, taken from an underlying coupled ocean-atmosphere general circulation model (OAGCM) simulation using the same GHG scenario; otherwise the SSTs are taken from a simulation of the Met Office's Hadley Centre Global Environmental Model version 1 (HadGEM1) OAGCM (Johns et al. 2006), again using the A1B GHG scenario; and

- surface halogens are prescribed according to the $\mathrm{Ab}$ scenario of WMO (2003).

The REF2 simulations include anthropogenic forcings but not natural forcings, such as variations in solar irradiance or big volcanic eruptions. On the other hand, the SCN2 simulations include an additional forcing representing 
a repetitive solar cycle under volcanically clean aerosol conditions. Those models that do not reproduce a quasibiennial oscillation (QBO) also include a relaxation forcing toward the observed QBO (Giorgetta and Bengtsson 1999) for the SCN2 simulations.

Table 2 summarizes the simulations used in this study and any differences from the REF2/SCN2 specification. For three of the models [E39C, Middle Atmosphere version of ECHAM4 with Chemistry (MAECHAM4CHEM), and UMSLIMCAT], the simulation only extended over the first two decades of the twenty-first century, and therefore the twenty-first century trends calculated for some diagnostics from these simulations are often not statistically significant and for clarity are excluded from some of the figures. Additionally, results for some models are absent from a particular figure because the relevant data were not available in the central database (e.g., gravity wave drag diagnostics were not available for every model; see section 4). The dynamical predictions of many of the individual simulations have already been reported in the literature. References to these predictions are included in Table 2 and at appropriate points throughout this paper. Here we concentrate on using the multimodel comparisons to investigate the robustness and/or uncertainties of the predictions.

\section{Stratospheric climate change}

\section{a. Temperature trends}

Because the surface temperature response in the simulations used in this study is strongly constrained by the prescribed SSTs, the main focus is on stratospheric change, and only the temperature trends above $300 \mathrm{hPa}$ are shown in this section. As expected from the prescribed increases in the concentrations of the GHGs, all of the models predict a global cooling of the annual mean stratosphere for the twenty-first century (Fig. 1a). Apart from the results for the E39C model and MAECHAM4CHEM below $50 \mathrm{hPa}$, these trends are statistically significantly different from zero at the $95 \%$ confidence level, where a lag-1 autocorrelation is used to account for the nonindependence of the residual values about the trend line (e.g., section 4 in Santer et al. 2008). In general there is good agreement between the models in the magnitude of the cooling, particularly in the lower and middle stratosphere, and all of them predict increased cooling with height in the stratosphere. This is consistent with the trends obtained from earlier transient simulations of the stratosphere-resolving GCMs without ozone feedbacks (e.g., Butchart et al. 2000), time-slice experiments with ozone feedbacks (e.g., Jonsson et al. 2004), and, more recently, the simulations performed for the IPCC Fourth Assessment Report
(AR4; e.g., Cordero and Forster 2006). In the middle to upper stratosphere (10-1 hPa) the models predict a maximum annual global mean cooling between 0.63 (MRI) and 1.08 (ULAQ) $\mathrm{K} \mathrm{decade}^{-1}$. When only the tropics $\left(30^{\circ} \mathrm{N}-30^{\circ} \mathrm{S}\right)$ are considered, the transition from tropospheric warming to stratospheric cooling becomes much more pronounced and occurs at a slightly higher altitude (cf. Figs. 1a,b). Again, the trends are nearly all statistically significantly different from zero at the $95 \%$ confidence level, except for the MAECHAM4CHEM trends below $50 \mathrm{hPa}$. In the tropics the trends predicted by the E39C model are statistically significant apart from between 115 and $70 \mathrm{hPa}$. For the five models (AMTRAC, CCSR/ NIES, CMAM, GEOS CCM, and MRI) that simulated the whole of the twenty-first century, there was very little difference between global and equatorial trends calculated for the first $50 \mathrm{yr}$ from those for the full $100 \mathrm{yr}$ shown in Fig. 1.

In general, in the high latitudes (i.e., poleward of $60^{\circ}$ ) there were large seasonal variations in the temperature trends predicted by the models. Figure 2 shows the vertical profile of the trends in the mean temperatures poleward of $60^{\circ}$ for the two solstice seasons for both hemispheres. In both seasons the high-latitude trends from the short 20-yr simulations of the E39C model, MAECHAM4CHEM, and UMSLIMCAT were not statistically significant, except in the Northern Hemisphere upper stratosphere and mesosphere during June-August for the MAECHAM4CHEM and UMSLIMCAT (the E39C model does not include the upper stratosphere or mesosphere in its domain). Because of this lack of statistical significance, the results from these three models were not included in the multimodel mean trends shown in the figure although the individual model predictions are shown.

For the austral summer all but two of the models predict a warming of the polar upper troposphere/lower stratosphere (Fig. 2a), similar to that found by Son et al. (2008) and is almost certainly a consequence of the recovery of ozone over Antarctica in the simulations (Eyring et al. 2007). Moreover, the spread in the amplitude of the predicted upper-tropospheric/lower-stratospheric warming, from about $0.3 \mathrm{~K}$ decade $^{-1}$ for the CMAM ensemble to up to $1 \mathrm{~K} \mathrm{decade}^{-1}$ for the WACCM ensemble, appears to be directly related to the predicted rate of ozone recovery. Figure 3 shows that poleward of $60^{\circ} \mathrm{S}$ during DecemberFebruary there is a good correlation across the multimodel ensemble between the predicted temperature trends at $100 \mathrm{hPa}$ and the projected trends in total ozone. For the eight models that simulated the period 2000-50 the correlation coefficient between the ozone and temperature trends was 0.83 with the slope of the least squares linear fit (solid line in Fig. 3), implying 


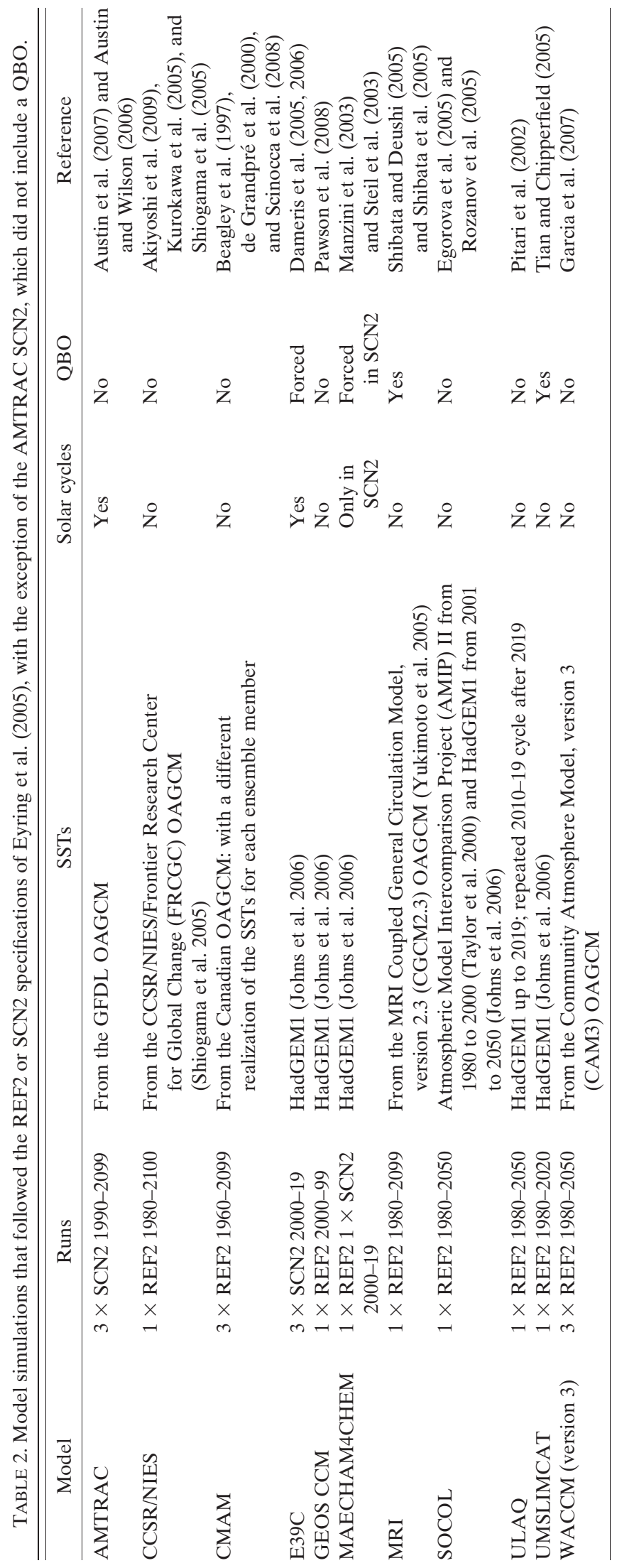


(a) Annual- and Global-Mean

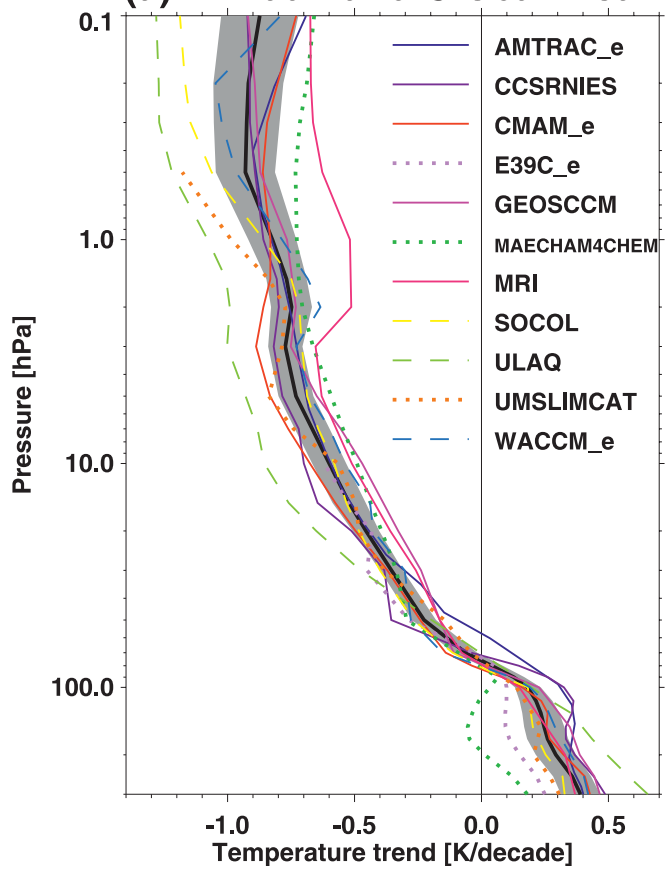

(b) Annual-Mean 30N-30S

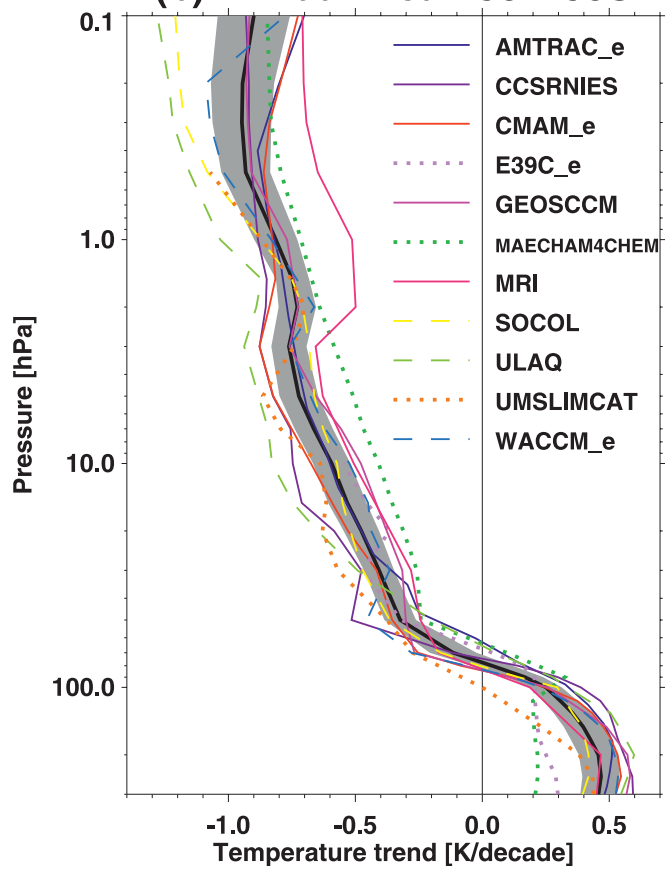

FIG. 1. Vertical profiles of the annual mean (a) global and (b) tropical $\left(30^{\circ} \mathrm{N}-30^{\circ} \mathrm{S}\right)$ temperature trends predicted for the twenty-first century. The trends were calculated from a least squares linear fit to the modeled temperature time series for the years of 2000-99 (solid curves) or to the end of the simulation if that was before 2099; that is, 2050 for the SOCOL, ULAQ, and WACCM simulations (dashed curves) and 2019 for the E39C, MAECHAM4CHEM, and UMSLIMCAT (dotted curves) simulations; see Table 2. The extension "_e" to a model short name indicates that the ensemble mean of more than one simulation was used to calculate the trend for that model. The black line is the multimodel mean with the gray shading denoting \pm two standard error (i.e., the multimodel standard deviation divided by $\sqrt{n}$, where $n$ is the number of models).

a $0.07 \mathrm{~K} \mathrm{decade}^{-1}$ increase in the rate of warming for each 1 DU decade ${ }^{-1}$ increase in the rate of ozone recovery. Extrapolating the linear fit to zero ozone trend suggests a warming trend at this level of $0.13 \mathrm{~K} \mathrm{decade}^{-1}$ attributable to the GHG-induced climate change (i.e., $0.13 \mathrm{~K} \mathrm{decade}^{-1}$ is the intercept in Fig. 3 for a zerocolumn ozone trend). Including results from the 2000-19 simulations of the E39C model and UMSLIMCAT reduces the correlation between the ozone and temperature trends only slightly from 0.83 to 0.81 and has very little impact on the slope or position of the least squares linear fit line. Five models (AMTRAC, CCSR/NIES, CMAM, GEOS CCM, and MRI) also provided predicted trends for 2050-99. Again, Fig. 3 shows that there is a good correlation between the models $(0.99$; but note the small sample size) with the linear fit being very similar to that obtained for the previous 50 years (a slope of 0.06 and an intercept of 0.17 for 2050-99 compared to 0.07 and 0.13 , respectively, for 2000-50). Also, Fig. 3 shows that during the second half of the century four out of the five models project a slower rate of ozone recovery (or increase), and hence warming at $100 \mathrm{hPa}$, compared to the first half of the century. On average, the rate of ozone recovery is about $30 \%$ less, with a corresponding decrease in the rate of warming from 0.8 to $0.48 \mathrm{~K} \mathrm{decade}^{-1}$.

The lower-stratospheric warming is accompanied by cooling of the middle stratosphere of the order of 0.8 $\mathrm{K}$ decade ${ }^{-1}$ with generally good agreement between the models (Fig. 2a). The $0.8 \mathrm{~K} \mathrm{decade}^{-1}$ cooling of the middle stratosphere is more than would be expected from the changes in the GHG concentrations [cf., Fig. 1a for the global annual mean; see also Fig. 4b of Hitchcock et al. (2009)], but the additional cooling accompanying the warming below is consistent with the temperature response that Kiehl et al. (1988) and Mahlman et al. (1994) found for a specified ozone hole. An explanation for this response was subsequently provided by Manzini et al. (2003) in terms of enhanced planetary wave drag in December-February from the delayed breakdown of the vortex. For the austral winter all of the models apart from the UMSLIMCAT and one E39C simulation indicate a cooling of the stratosphere, which increases with height, as does the spread between models (Fig. 2b).

For the boreal winter there is good agreement between six of the eight simulations that extended to 2050 and beyond, with almost zero trend in the lower 
(a) Dec-Jan-Feb 60S-90S

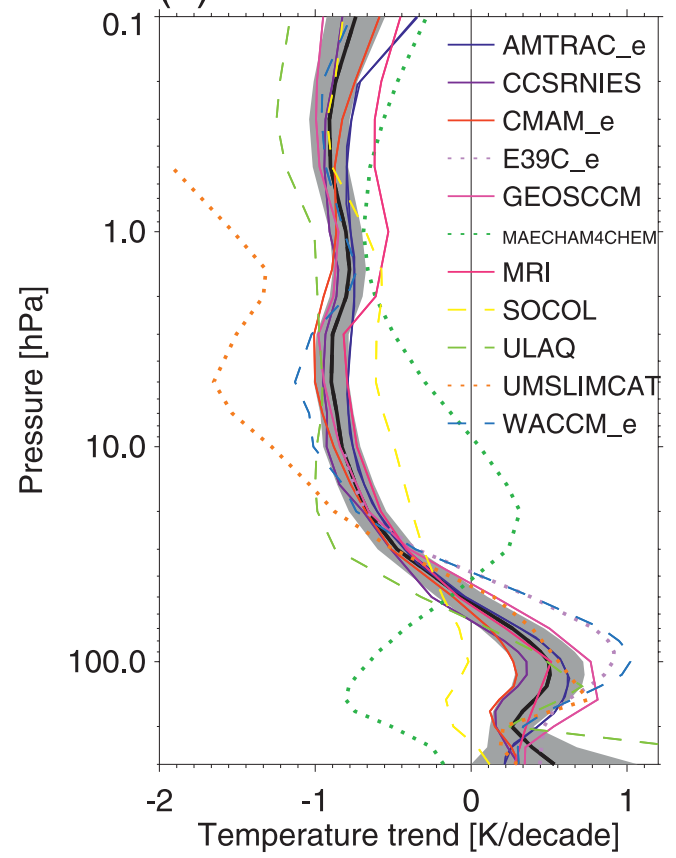

(c) Dec-Jan-Feb 60N-90N

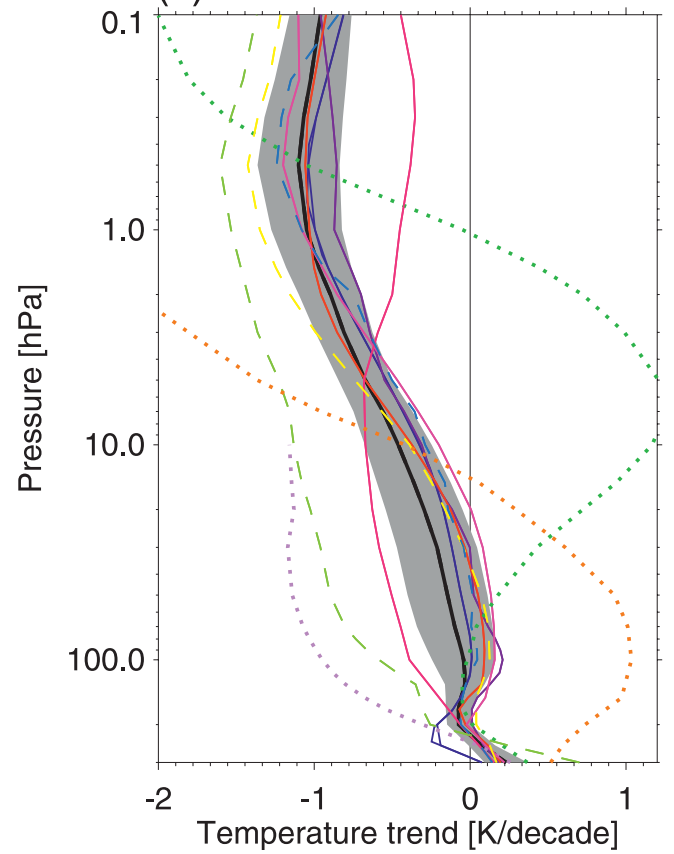

(b) Jun-Jul-Aug 60S-90S

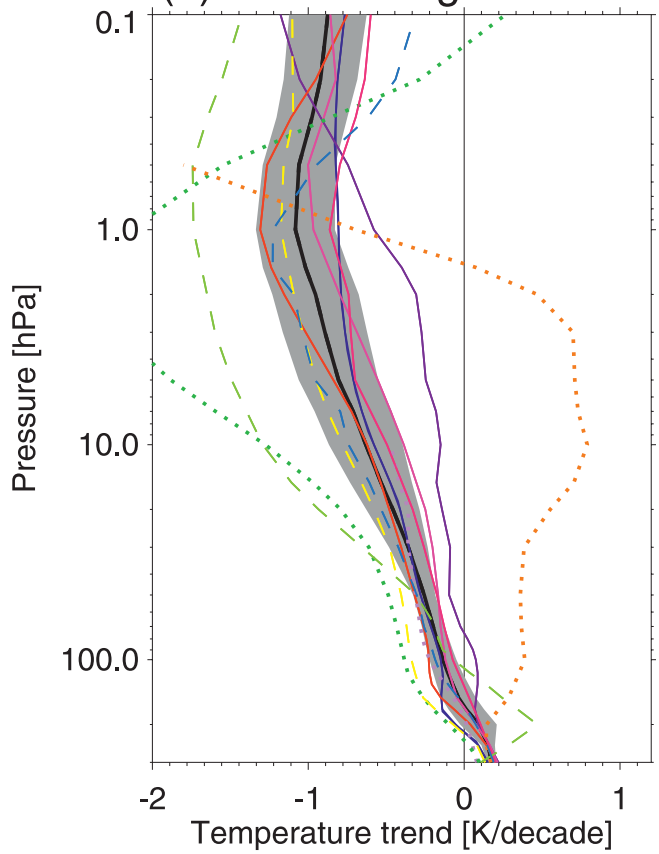

(d) Jun-Jul-Aug 60N-90N

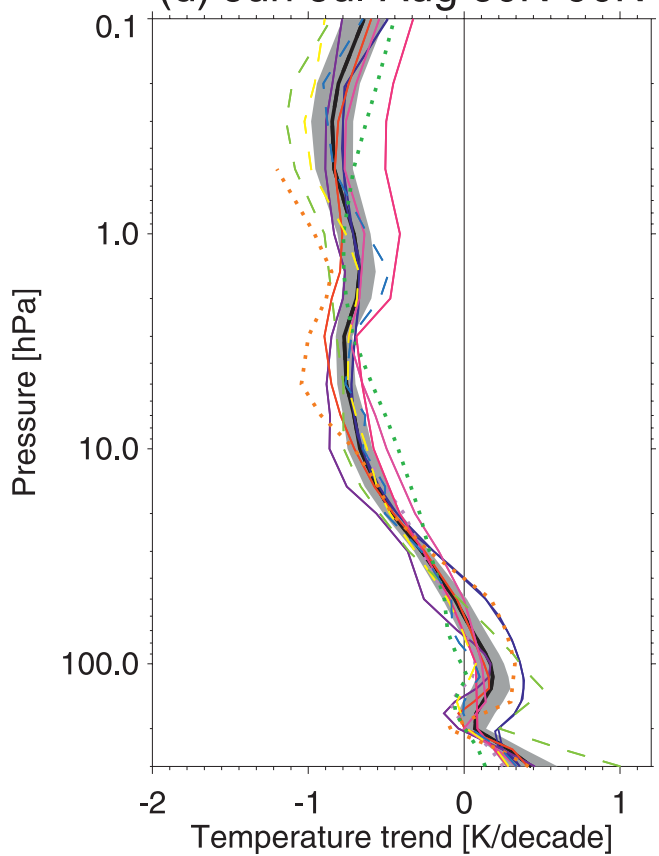

FIG. 2. As in Fig. 1, but for the temperatures averaged between $60^{\circ}$ and $90^{\circ} \mathrm{S}$ for (a) December-February, and (b) June-August, and averaged between $60^{\circ}$ and $90^{\circ} \mathrm{N}$ for (c) December-February, and (d) June-August.

stratosphere and cooling in the middle and upper stratosphere (Fig. 2c). The MRI and ULAQ models are the exceptions. In the other six models the near-zero future trend in the lower stratosphere, which also extends into spring (not shown), contrasts with the results of Austin et al. (2009) who found that when the same models were used to stimulate the recent past there was cooling in this region in February-April. Although this difference in the past and future responses in spring suggests that the projected recovery of Arctic ozone in the twenty-first century (Eyring et al. 2007) is perhaps having a direct effect on the model temperatures, this would be unlikely during 


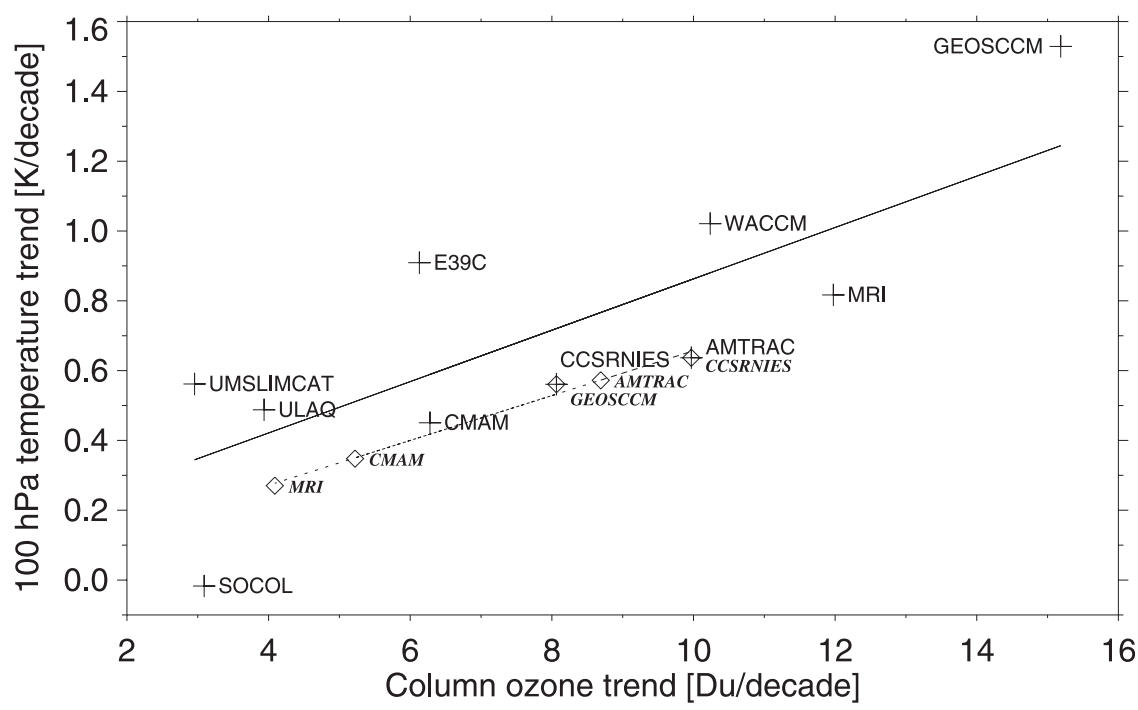

FIG. 3. Scatter diagram of the trend in the December-February mean column ozone at $60^{\circ}$ $90^{\circ} \mathrm{S}$ against the trend in the $100-\mathrm{hPa}$ temperatures averaged over the same 3 months and region. The trends for 2000-50 (crosses; 2000-19 for E39C and UMSLIMCAT) and the trends for 2050-99 for the five models for which the simulations extended to 2099 (diamond symbols with model short names in italics). The solid (dotted) line is the least squares linear fit to the results for 2000-50 (2050-99). When results for more than one simulation were available for a particular model, the trends were calculated from the ensemble mean.

the polar night (i.e., midwinter). A more likely explanation for the winter period is that the climate change in the simulations increases adiabatic warming of the Northern Hemisphere polar stratosphere so that it more or less balances the extra radiative cooling from the increased amounts of GHGs. Consistent with this, the mean downwelling in the lower stratosphere $(\sim 50 \mathrm{hPa})$ poleward of $60^{\circ} \mathrm{N}$ increased by $0.6 \%$ decade $^{-1}$ for the AMTRAC and CCSR/NIES model, $0.8 \%$ decade $^{-1}$ for the WACCM, $1.6 \%$ decade $^{-1}$ for the CMAM, $1.9 \%$ decade $^{-1}$ for the GEOS CCM, and $3.5 \%$ decade $^{-1}$ for the Solar Climate Ozone Links (SOCOL) model, though apart from the CMAM and GEOS CCM results these trends are not statistically significant. In the other two long simulations (MRI and ULAQ) the polar downwelling decreased (and also was not statistically significant), again consistent with the temperature trends in Fig. $2 \mathrm{c}$ for those two models. However, because the ULAQ simulation lacks any long-term trend in its surface forcing (see Table 2), the ULAQ temperature and downwelling trends are less certain than those obtained from the other models. Therefore, based on the multimodel ensemble, the increased adiabatic warming of the Northern Hemisphere polar lower winter stratosphere can almost certainly be considered as a robust feature of climate change. For the boreal summer there is reasonably good agreement between the models (Fig. 2d) and the trends have broadly the same features as those for the global mean temperatures.

\section{b. Polar stratospheric cloud formation}

During times of elevated amounts of halogens, changes in stratospheric temperatures are expected to have a large impact on polar ozone loss through the formation and occurrence of PSCs. Following Pawson et al. (1999) and Austin et al. (2003), Fig. 4 shows a time series of seasonally accumulated areas for the Antarctic (JulyDecember) and the Arctic (November-April), where the daily temperature poleward of $60^{\circ}$ is below $195 \mathrm{~K}$ (approximate NAT and STS threshold temperature, upper row) and below $188 \mathrm{~K}$ (approximate ice threshold temperature, middle row) for the models (colored lines) and 40-yr European Centre for Medium-Range Weather Forecasts (ECMWF) Re-Analysis (ERA-40; black dashed line). The quantity used in Fig. 4 is the percentage of the horizontal area of the hemisphere where the $50-\mathrm{hPa}$ temperatures poleward of $60^{\circ}$ are below the NAT and ice PSC formation thresholds. These daily percentage areas are then accumulated over the course of the winter and spring (July-December in the SH, and DecemberApril in the $\mathrm{NH}$ ) to provide, for that year, an estimate of the total amount of NAT and ice PSCs in units of percent days, as shown in the figure.

In the Antarctic, the magnitude of the multimodel mean temperature-derived NAT $\left(T_{\mathrm{NAT}}\right)$ and ice $\left(T_{\text {ice }}\right)$ PSC area agrees well with the ERA-40 data, although it should be cautioned that these quantities and their 

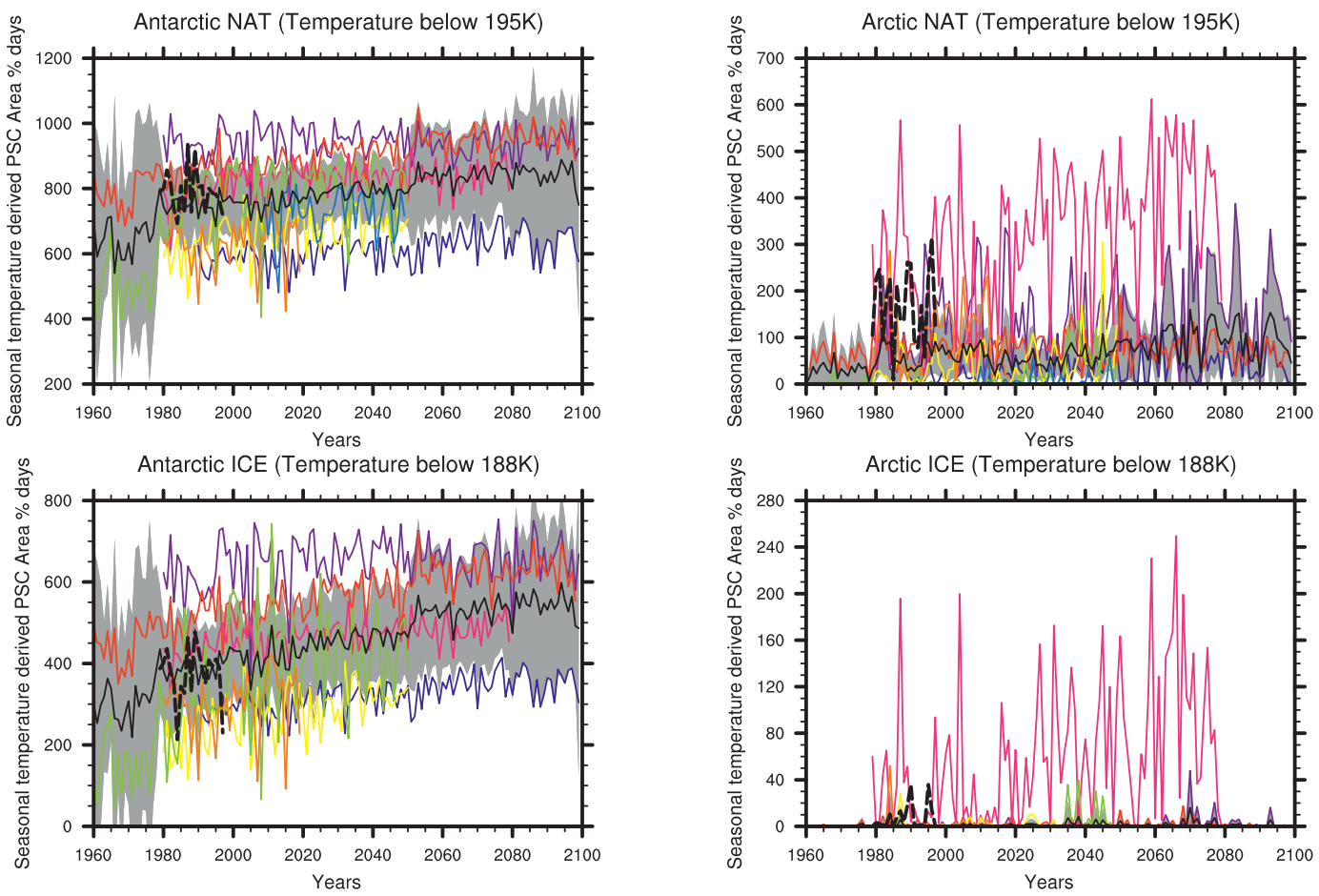

Antarctic NAT (actual PSC area)
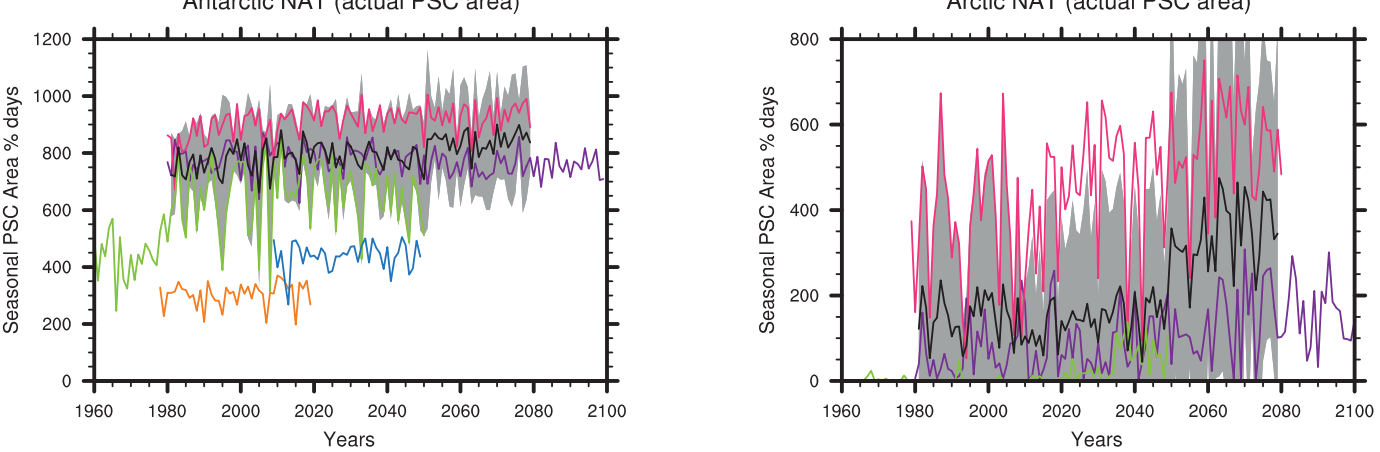

AMTRAC
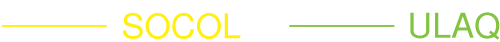

\section{- - - ERA40}

\section{MULTIMODEL MEAN}

FIG. 4. Seasonal accumulation of the (left) Antarctic (July-December) and (right) Arctic (November-April) area at $50 \mathrm{hPa}$, where daily temperatures are (top) below $195 \mathrm{~K}$ (approximate threshold temperature for NAT and STS formation) and (middle) below $188 \mathrm{~K}$ (approximate threshold temperature for ice formation) for the models (colors) and ERA-40 (black-dashed line). (bottom) The actual PSC area in the models, which was available only from a subset of models (CCSR/NIES, MRI, ULAQ, UMSLIMCAT, and WACCM). The solid black line is the multimodel mean with the gray shading denoting two standard error as in Fig. 1. In the lower panel UMSLIMCAT and WACCM are excluded from the multimodel mean, because they only cover a short period and produce jumps in the multimodel mean if included.

trends are hard to derive from global assimilation data and often depend on which analysis or reanalysis datasets are used (e.g., Manney et al. 2003, 2005). The majority of the models show an increase in $T_{\mathrm{NAT}}$ in all time periods (the entire REF2 simulation, 1980-99, 2000-49, and 2050-99; see also Table 3). Only the UMSLIMCAT and the CCSR/NIES model simulate negative trends, but these negative trends are not statistically significant 
TABLE 3. Linear trends in Arctic and Antarctic PSC areas at $50 \mathrm{hPa}$ for each model derived for different periods (entire time period of REF2 simulations, 1980-99, 2000-49, and 2050-99). Trends that are statistically significant at the 95\% confidence level are shown in bold. In addition to the individual models, the multimodel mean is given.

\begin{tabular}{|c|c|c|c|c|c|c|c|}
\hline \multirow[b]{2}{*}{ Model } & \multirow[b]{2}{*}{ Period } & \multicolumn{3}{|c|}{$\mathrm{NH} 60^{\circ}-90^{\circ} \mathrm{N}$ at $50 \mathrm{hPa}$} & \multicolumn{3}{|c|}{$\mathrm{SH} 60^{\circ}-90^{\circ} \mathrm{S}$ at $50 \mathrm{hPa}$} \\
\hline & & $T_{\mathrm{NAT}} / A_{\mathrm{PSC}}$ & $T_{\text {ice }}$ & Actual PSC area & $T_{\mathrm{NAT}} / A_{\mathrm{PSC}}$ & $T_{\text {ice }}$ & Actual PSC area \\
\hline ERA-40 & 1979-2006 & $-1.78 / 0.16$ & 0.68 & - & $-0.36 / 0.08$ & 4.87 & - \\
\hline \multirow[t]{4}{*}{ AMTRAC } & 1990-2099 & $0.32 / 0.02$ & 0.0 & - & $0.72 / 0.02$ & 0.79 & - \\
\hline & 1990-99 & $0.76 / 0.01$ & 0.0 & - & $2.18 /-0.04$ & 0.48 & - \\
\hline & $2000-49$ & $0.89 / 0.03$ & 0.0 & - & $0.66 / \mathbf{0 . 0 2}$ & 0.83 & - \\
\hline & 2050-99 & $0.05 /-0.02$ & 0.01 & - & $0.51 / 0.01$ & 0.58 & - \\
\hline \multirow[t]{4}{*}{ CCSR/NIES } & 1980-2050 & $0.68 / 0.02$ & 0.03 & 1.03 & $-0.01 / 0.0$ & 0.35 & -0.29 \\
\hline & 1980-99 & $5.95 / 0.13$ & 0.03 & 3.96 & $1.01 /-0.02$ & 2.80 & 1.85 \\
\hline & $2000-49$ & $0.49 / 0.01$ & 0.01 & 1.01 & $0.35 /-0.01$ & 1.19 & 0.00 \\
\hline & 2050-99 & $0.98 / 0.02$ & 0.01 & 1.26 & $0.26 / 0.00$ & -0.06 & -0.01 \\
\hline \multirow[t]{4}{*}{ CMAM } & 1960-2099 & $-0.03 / 0.00$ & 0.0 & - & 1.33/0.04 & 1.49 & - \\
\hline & 1980-99 & $-0.54 /-0.06$ & -0.08 & - & $4.01 / 0.12$ & 4.02 & - \\
\hline & $2000-49$ & $-0.53 /-0.01$ & -0.03 & - & $1.27 / 0.05$ & 1.46 & - \\
\hline & 2050-99 & $-0.60 /-\mathbf{0 . 0 3}$ & - & - & $0.11 / \mathbf{0 . 0 0}$ & 0.11 & - \\
\hline \multirow[t]{4}{*}{ MRI } & 1980-2099 & 2.19/0.05 & 0.79 & 2.48 & $\mathbf{0 . 6 7 / 0 . 0 1}$ & 0.64 & 0.75 \\
\hline & 1980-99 & $1.70 /-0.11$ & -0.45 & 1.85 & $6.16 / 0.15$ & 4.4 & 6.50 \\
\hline & $2000-49$ & $2.42 / 0.05$ & 1.06 & 2.62 & $\mathbf{0 . 6 8} / 0.01$ & 0.73 & 0.79 \\
\hline & 2050-99 & $0.29 / 0.09$ & -0.02 & 1.33 & $0.78 / 0.00$ & 0.61 & 1.10 \\
\hline \multirow[t]{3}{*}{ SOCOL } & 1980-2050 & $0.64 / 0.06$ & -0.02 & - & $1.46 / 0.04$ & 1.77 & - \\
\hline & 1980-99 & $1.22 / 0.16$ & -0.15 & - & $6.41 / 0.15$ & 5.68 & - \\
\hline & $2000-49$ & $0.79 / \mathbf{0 . 0 9}$ & -0.02 & - & $1.05 /-0.003$ & 1.47 & - \\
\hline \multirow[t]{3}{*}{ ULAQ } & 1980-2050 & $0.63 / 0.03$ & 0.09 & 0.70 & $3.59 / 0.12$ & 3.48 & 2.46 \\
\hline & 1980-99 & $0.18 / 0.01$ & 0.01 & 0.14 & $5.24 / 0.11$ & 7.51 & 3.06 \\
\hline & $2000-49$ & 1.58/0.07 & 0.22 & 1.77 & $0.64 / 0.00$ & 0.52 & -0.62 \\
\hline \multirow[t]{2}{*}{ UMSLIMCAT } & 1980-2020 & $-0.35 / 0.04$ & -0.15 & -1.41 & $0.58 / 0.01$ & 0.80 & -1.10 \\
\hline & 1980-99 & $-1.3 /-0.14$ & -0.47 & -2.4 & $-4.03 / 0.04$ & -3.59 & $-\mathbf{3 . 3 3}$ \\
\hline \multirow[t]{2}{*}{ WACCM } & 1980-2050 & $-0.09 / 0.01$ & - & -0.01 & $0.69 / 0.02$ & - & 0.44 \\
\hline & $2009-50$ & $-0.09 /-0.01$ & - & -0.01 & $0.07 / 0.02$ & - & 0.44 \\
\hline \multirow[t]{4}{*}{ Multimodel mean } & 1980-2099 & $\mathbf{0 . 5 1} / 0.02$ & 0.0 & 2.70 & $1.43 / 0.04$ & 1.89 & 0.93 \\
\hline & 1980-99 & $0.32 / 0.00$ & -0.23 & 0.75 & $0.90 /-0.04$ & 2.01 & 3.47 \\
\hline & $2000-49$ & $0.08 / 0.00$ & 0.23 & 0.65 & $1.90 / 0.03$ & 1.49 & -1.35 \\
\hline & 2050-99 & $\mathbf{0 . 1 3} / 0.01$ & 0.67 & 2.76 & $0.19 / 0.01$ & 0.63 & 1.20 \\
\hline
\end{tabular}

in any of the time periods. For each model that shows positive trends, the increase in $T_{\mathrm{NAT}}$ is largest in the 1980-99 period. A further, but smaller, increase is simulated in the first half of the twenty-first century and an even smaller positive trend occurs in the second half of the twenty-first century. The change in magnitude of the positive trend for the different time periods is consistent with the radiative effects of simulated ozone depletion between 1980 and 1999 and ozone recovery in the twentyfirst century, in addition to continued cooling of the stratosphere resulting from the prescribed increases in GHG amounts (Eyring et al. 2006, 2007). A similar result is found if, instead of the percentage of the hemisphere covered times their duration (days), the temperaturederived NAT PSC area is plotted $\left(\mathrm{km}^{2} ; A_{\mathrm{PSC}}\right)$ at $50 \mathrm{hPa}$ and the long-term trend is calculated from the maximum values of $A_{\mathrm{PSC}}$ for 5-yr intervals, as in Rex et al. (2006; see also our Fig. 5). Hitchcock et al. (2009) analyzed $A_{\mathrm{PSC}}$ at $50 \mathrm{hPa}$ in the three CMAM simulations used here and found that for that model the trends in $A_{\mathrm{PSC}}$ were a direct radiative consequence of changes in ozone and GHG amounts and were not the result of adiabatic changes in temperature. The trends in $T_{\text {ice }}$ in the models show similar features. Overall, there is clearly an increase in colder winters in the Antarctic with temperature extremes below 195 and $188 \mathrm{~K}$ favoring NAT and ice formation in the years of ozone depletion (1980-99); however, the positive trend is decreasing over the twenty-first century in all of the models (see Table 3).

In the Arctic, the situation is not as obvious as in the Antarctic. There are large differences among the simulations in both the absolute values and variability. For example, the MRI model overestimates $T_{\mathrm{NAT}}$ and $T_{\text {ice }}$ compared to the ERA-40 data. This result is consistent with a cold bias in this model in the Arctic winter at this altitude (e.g., Fig. 1 in Eyring et al. 2006). Consistently, the CCSR/NIES model is also on the high side. On average, most other models underestimate $T_{\mathrm{NAT}}$ compared to ERA-40 and the multimodel mean for $T_{\mathrm{NAT}}$ is slightly lower than that derived from the reanalysis data. 
The models are more consistent in the simulated trends. For the periods of 1980-99, 2000-49, and 2050-99, the simulated trends in $T_{\mathrm{NAT}}$ are only statistically significant in two of the models (AMTRAC and ULAQ). Three models (CMAM, UMSLIMCAT, and WACCM) simulate negative trends, but again none of these trends is statistically significant in any time period. In the CMAM the lower trends in the last decades of the twentieth century could be due to weaker ozone depletion simulated in that model compared to the observations (Hitchcock et al. 2009). Consistently, the UMSLIMCAT and WACCM, which also simulate smaller ozone depletion than that observed (Eyring et al. 2006, their Fig. 15), show negative trends in $T_{\mathrm{NAT}}$. A possible reason for the underestimation of ozone depletion by the CMAM is the absence of a NAT PSC parameterization (Hitchcock et al. 2009). All of the other models simulate positive trends that are statistically significant only in some simulations and for some time periods (2000-49 in the AMTRAC and ULAQ model, 1990-2099 in the AMTRAC, and 1980-2050 in the CCSR/NIES, SOCOL and ULAQ models). The multimodel mean indicates a small but statistically significant increase in $T_{\mathrm{NAT}}$ for the second half of the twenty-first century and a statistically significant increase of $0.51 \%$ days in the seasonally derived PSC area between 1980 and 2099. The multimodel mean for $T_{\text {ice }}$ shows an increase in trends from 1980-99 to 2000-49, which is mainly due to the increase in $T_{\text {ice }}$ in the MRI model. However, the multimodel mean trends that are given in Table 3 should be carefully interpreted, in particular for the periods of 2050-99 and 1980-2099, because the simulations from different models cover different periods, which produces jumps in the multimodel mean, for example, in 2050. The trends calculated from the maximum values of $A_{\text {PSC }}$ for 5-yr intervals in the models (Fig. 5, lower panel) are all smaller than the trends in $T_{\mathrm{NAT}}$, but they agree well in sign and statistical significance for the individual models. In particular, none of the models simulates an increase in the magnitude of the trend from $1980-99$ to $2000-49$ and from $2000-49$ to $2050-99$ that is statistically significant, indicating that there is no significant increase in Arctic PSC occurrence throughout the twenty-first century. This result is consistent with the small changes in monthly mean temperatures at $50 \mathrm{hPa}$ that are simulated by the models in January-February throughout the twenty-first century in the Arctic (see Fig. 2).

The above conclusions are based on daily temperatures. However, while the temperature for NAT and STS formation is typically about $195 \mathrm{~K}$ in the stratosphere, the exact value depends on the partial pressures of water vapor and nitric acid (Hanson and Mauersberger 1988).
The lower panels in Fig. 4 show the actual PSC area that is calculated by the model's PSC schemes, though this was only available from five models (CCSR/NIES, MRI, ULAQ, UMSLIMCAT, and WACCM). Both in the Antarctic and the Arctic, trends in the actual PSC area simulated by these models are similar to the temperaturederived PSC trends, except for the UMSLIMCAT, which shows a large statistically significant positive trend between 2000 and 2020, but a negative trend in $T_{\mathrm{NAT}}$. The absolute values for $T_{\mathrm{NAT}}$ (upper panels in Fig. 4) and the actual PSC area (lower panels in Fig. 4) differ in the models, especially in the UMSLIMCAT and the WACCM where the actual PSC area is lower than the temperaturederived PSC area. In addition, the magnitude of the actual PSC area differs among the models. Table 4 shows that there is a good correlation between the trends in Antarctic PSC areas at $50 \mathrm{hPa}$ derived from daily temperatures below $195 \mathrm{~K}$ (NAT) and the actual PSC area. The correlation coefficients are calculated for the five models plus the multimodel mean for the periods of 1980-99, 2000-49, and the entire simulation, and from two models and the multimodel mean for 2050-99. For the five models that provided this additional PSC diagnostic the correlation coefficient between the Antarctic temperature-derived and the actual PSC area was 0.86, with the slope of the least squares linear fit line implying a $0.91 \%$ increase in the fraction of $T_{\mathrm{NAT}}$ for each percent increase of the fraction in the actual PSC area. An interesting feature is that the correlation between $T_{\mathrm{NAT}}$ and the actual PSC area decreases from the past to the future, that is, the correlation coefficient is highest for 1980-99, decreases for 2000-49, and further decreases for 2050 99. The correlation in the Arctic between trends in $T_{\mathrm{NAT}}$ and the actual PSC area is smaller than the correlation in the Antarctic for the entire simulation but is higher for the shorter periods (1980-99, 2000-49, 2050-99; see Table 4).

\section{c. Zonal mean winds}

Changes in the zonal mean eastward wind can impact both the resolved (Rossby) wave propagation characteristics in the models and the filtering of the parameterized subgrid-scale gravity waves (see section $4 \mathrm{c}$ ). In the models the latitudinal dependence of the trends in the zonal and seasonal mean temperatures (cf. section $3 \mathrm{a}$ and Figs. $1 \mathrm{~b}$ and 2) alters both the meridional temperature gradients in the lower stratosphere and the zonal mean zonal winds, thus maintaining thermal wind balance. Figure 6 shows the trends in the eastward winds at $70 \mathrm{hPa}$ for the two solstice seasons for those simulations that extended to at least 2050. Except at the latitudes where the trends change sign, all of the trends shown are statistically significantly different from zero at the $95 \%$ 

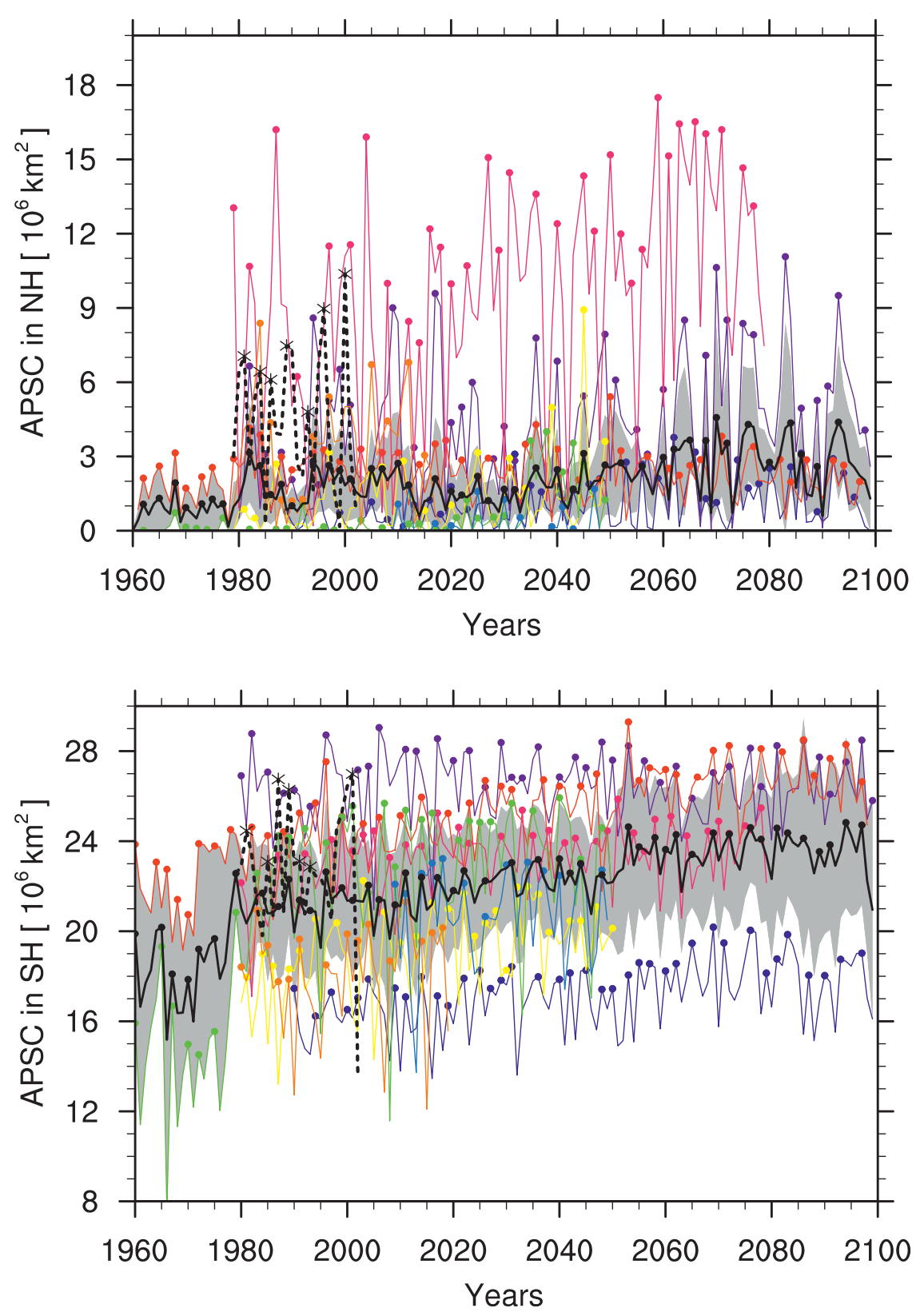

FIG. 5. (top) Antarctic (July-December) and (bottom) Arctic (November-April) PSC area at $50 \mathrm{hPa}\left(\mathrm{km}^{2} ; A_{\mathrm{PSC}}\right)$ from the models (colors) and ERA-40 (black dashed line). The solid black line is the multimodel mean with the gray shading denoting two standard errors. The long-term trend in the simulations and the ERA-40 data is calculated from the maximum values of $A_{\text {PSC }}$ for 5-yr intervals, which are displayed as circles. Note the different scale between the top and bottom panels.

confidence level, again using a lag-1 autocorrelation to account for the nonindependence of the residual values about the trend line.

Although there is quite a broad spread in the trends shown in Fig. 6, most of the simulations exhibited the same basic features that were present throughout the lower stratosphere (e.g., similar figures were obtained for the trends at 100 and $50 \mathrm{hPa}$, not shown). The main exception is the ULAQ simulation, especially in the Northern Hemisphere. Most likely this is a consequence of the poor representation of the upper-tropospheric dynamics in that model resulting from its quasigeostrophic formulation and coarse vertical resolution, though it should also be noted that there is no long-term trend in 
TABLE 4. Correlation coefficient and slope of the least squares linear fit for $\mathrm{T}_{N A T}$ and the actual PSC area.

\begin{tabular}{lcc}
\hline Trend period & $\begin{array}{c}\text { Correlation/slope } \\
\text { in NH }\end{array}$ & $\begin{array}{c}\text { Correlation/slope } \\
\text { in SH }\end{array}$ \\
\hline Entire simulation & $0.64 / 0.48$ & $0.86 / 0.91$ \\
$1980-99$ & $0.98 / 1.57$ & $0.90 / 1.03$ \\
$2000-49$ & $0.98 / 1.03$ & $0.85 / 0.59$ \\
$2050-99$ & $-0.67 /-0.36$ & $0.32 / 0.15$ \\
\hline
\end{tabular}

the SST forcing in the ULAQ simulation (see Table 2). Because of these deficiencies the results from the ULAQ simulation are not included in the multimodel mean shown in Fig. 6.

In the subtropics all of the models predict an eastward acceleration in the zonal mean wind in both hemispheres and seasons corresponding to a strengthening of the subtropical jets in the models. For the Northern Hemisphere winter the models fall into two categories. In the AMTRAC and MRI simulations the eastward acceleration extends over the entire extratropics and peaks in the midlatitudes. In the CCSR/NIES, CMAM, GEOS CCM, SOCOL, and WACCM simulations the eastward acceleration peaks in the subtropics and decreases or even changes sign on moving toward the pole. The reasons why the models fall into two categories is unclear, but most likely it is due to the uncertainty in sign of the high-latitude response, which is strongly influenced by changes in wave driving and is not robust among the models. In contrast, the eastward acceleration of the subtropical jets results directly from the radiative-convective warming of the tropical upper troposphere and therefore consistently has the same sign for all of the models.

In the high-latitude Southern Hemisphere summer all of the models apart from the SOCOL model indicate a westward acceleration (Fig. 6a) that is consistent with the warming trends in the lower stratosphere in Fig. 2a, resulting from the recovery in the Antarctic ozone [Fig. 3; see also Son et al. (2008)]. Those simulations with the strongest warming trends in Fig. 2 (e.g., WACCM and GEOS CCM) were also the simulations with the largest westward acceleration apart from that for the ULAQ model. In some of the simulations this westward trend in the seasonal mean zonal winds is, in part, due to the earlier transition from the winter eastward jet to the summer westward jet. This is consistent with other (a) Dec-Jan-Feb $70 \mathrm{hPa}$

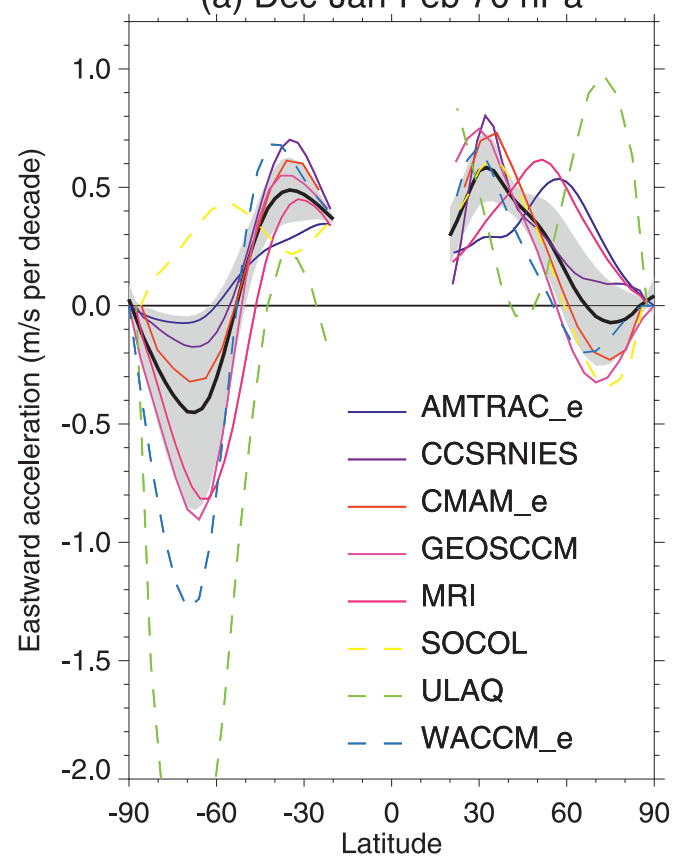

(b) Jun-Jul-Aug $70 \mathrm{hPa}$

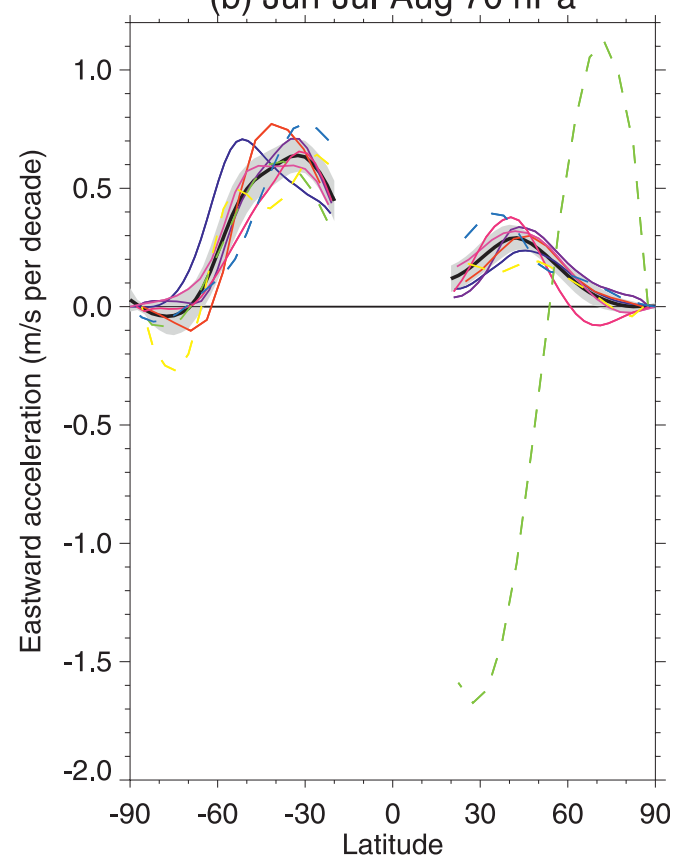

FIG. 6. Trends in the zonal mean eastward wind at $70 \mathrm{hPa}$ as a function of latitude for (a) December-February and (b) June-August. The trends were calculated from a least squares linear fit to the modeled time series of the zonal mean eastward wind for the years 2000-99 for the AMTRAC, CCSR/NIES, CMAM, GEOS CCM, and MRI simulations (solid curves), and for the years 2000-50 for the SOCOL, ULAQ, and WACCM3 simulations (dashed curves). The extension_e to a model short name indicates that the ensemble mean of more than one simulation was used to calculate the trend for that model. The black line is the multimodel mean (excluding ULAQ; see the text), with the gray shading denoting \pm two standard error. 
results that have shown that the presence of an Antarctic ozone hole can delay the breakdown of the Southern Hemisphere polar vortex (e.g., Akiyoshi et al. 2009).

\section{Brewer-Dobson circulation}

\section{a. Tropical upwelling}

Apart from the short (20 yr) simulations from the E39C and MAECHAM4CHEM models, all of the simulations show a clear positive trend in the annual mean tropical upwelling mass flux in the lower stratosphere (Fig. 7), consistent with previous studies (e.g., Butchart and Scaife 2001; Butchart et al. 2006; Li et al. 2008; McLandress and Shepherd 2009). As in Butchart et al. (2006), there is quite a wide spread between the simulations in the strength of the upwelling (ranging from roughly 5 to $7 \mathrm{Mt} \mathrm{s}^{-1}$ around the year $2000^{1}$ for the annual mean; see also Fig. 11), though this spread is much smaller $\left(\sim 0.2 \mathrm{Mt} \mathrm{s}^{-1}\right)$ for simulations from the same model (see the AMTRAC, CMAM, E39C model, or WACCM results in Fig. 7, where the line thickness indicates the spread between ensemble members). Indeed, for the AMTRAC, CMAM, E39C model, and WACCM, the spread between ensemble members is much less than the interannual variability.

For the majority of the models Fig. 7 shows that the amplitude of the annual cycle is larger than the interannual variability in either the seasonal or annual mean upwelling. In general the strongest upwelling occurs during the boreal winter (dark gray curves) and the weakest during the boreal summer (light gray curves), with the amplitude of the annual cycle typically about $1 \mathrm{Mt} \mathrm{s}^{-1}$. The SOCOL and ULAQ results were an exception, with the SOCOL model having a rather weak annual cycle and the ULAQ model having the incorrect phase. The reasons for this peculiar behavior are unclear because both of these models correctly reproduced the annual cycle in the 100-hPa temperatures at the equator (see Fig. 7 of Eyring et al. 2006). Figure 7 confirms the findings of Butchart and Scaife (2001) and Butchart et al. (2006), indicating that the increases in tropical upwelling occurs throughout the year (or at least in both the solstice seasons shown in the figure).

The positive trend in the annual mean tropical upwelling is a robust feature of the multimodel ensemble at all stratospheric levels, that is, the predicted strengthening of the Brewer-Dobson circulation is not a shallow

\footnotetext{
${ }^{1}$ Note that the AMTRAC results were provided at $77 \mathrm{hPa}$ and not $70 \mathrm{hPa}$, and therefore the upwelling mass flux shown for the AMTRAC in Figs. 7 and 11 probably slightly overestimates the mass flux at $70 \mathrm{hPa}$ because the upwelling mass flux generally decreases with height in the lower stratosphere.
}

feature, but extends into the upper stratosphere (see Fig. $8 \mathrm{a})$. At $70 \mathrm{hPa}$ the multimodel mean trend is just under $2 \%$ decade $^{-1}$ and slightly less than that estimated by Butchart et al. (2006), though the difference can probably be attributed to the choice of year with respect to which the percentages were calculated. For the percentage trend in the annual mean upwelling (Fig. 8a) all of the models exhibit the same features with a minimum, but still positive, trend in the middle stratosphere and an increasing trend with altitude above that. Similar behavior can be seen in the trends for the solstice seasons (Figs. $8 \mathrm{~b}, \mathrm{c})$ though there is a greater spread between the models, and one model (SOCOL) predicts a negative trend in the lower to middle stratosphere in June-August.

\section{b. Age of air}

Mean age of air is defined as the mean time that a stratospheric air mass has been out of contact with the well-mixed troposphere and provides valuable information on the integrated transport within the stratosphere. For the REF2 simulations, age-of-air diagnostics were available in the central database for the following five models: AMTRAC, CMAM, GEOS CCM, ULAQ, and WACCM. When these models were used to simulate the recent past, Eyring et al. (2006) found that at $50 \mathrm{hPa}$ there was very good agreement among the models and with the age inferred from observations of trace constituents. However, they found larger differences in the upper stratosphere, both between the models and between the models and observations. In particular, the AMTRAC, CMAM, GEOS CCM, and WACCM all had a lower age of air than that observed and the ULAQ model had air that was older than that observed. The mean age of air in the REF2 simulations for the year 2000 is shown in Fig. 9 (see figure legend for details). The overall age distributions are similar in all models, but there are quantitative differences. The largest deviations between the models are generally in regions where the air is really old. In particular, the air in the CMAM's and ULAQ's upper stratosphere and mesosphere and in the GEOS CCM's extratropical lower stratosphere is more than $0.6 \mathrm{yr}$ older than the multimodel mean age (Fig. 9 bottom right) of 4-5 $\mathrm{yr}$ in these regions.

Comparing Figs. 7 and 9 suggests that to a large extent the intermodel differences in the mean age of air can be attributed to the differences in the strength of the Brewer-Dobson circulation or more precisely the tropical upwelling at $70 \mathrm{hPa}$. The two models with the strongest upwelling (the AMTRAC and WACCM) have the youngest air (blue shading in Figs. 9a,e). For the five models considered, this relationship between the strength of the upwelling and mean age of air appears to be true throughout most of the stratosphere and mesosphere, but 
AMTRAC_e

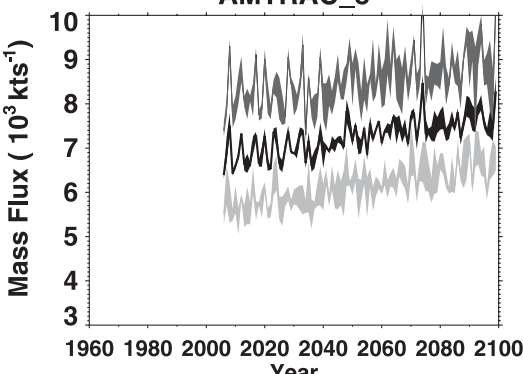

Year

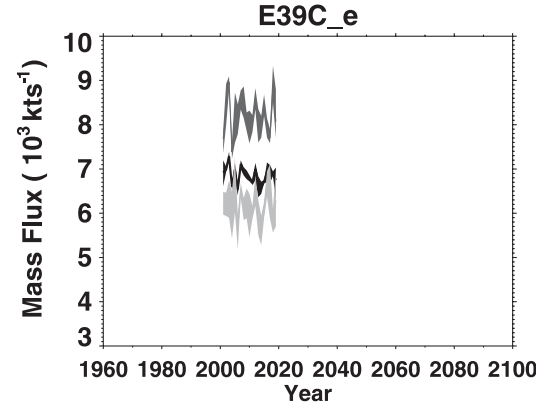

MRI

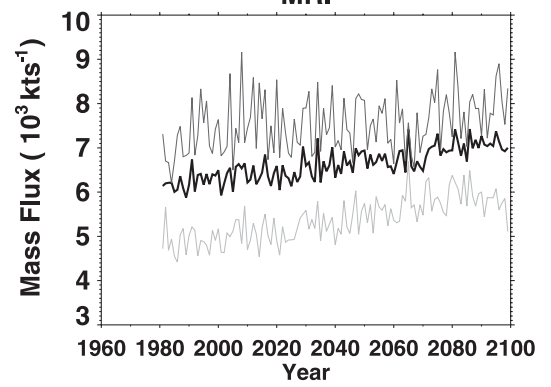

WACCM e

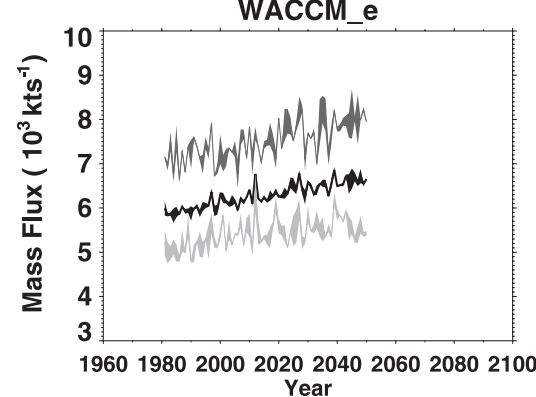

CCSRNIES

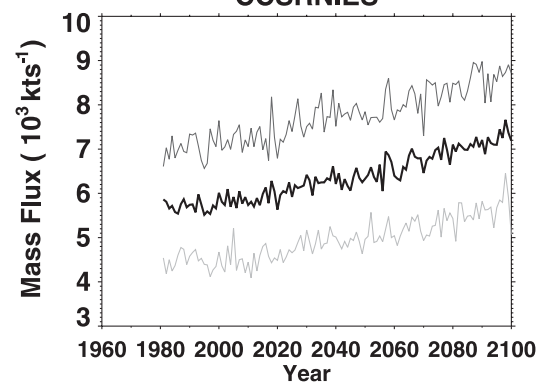

GEOSCCM
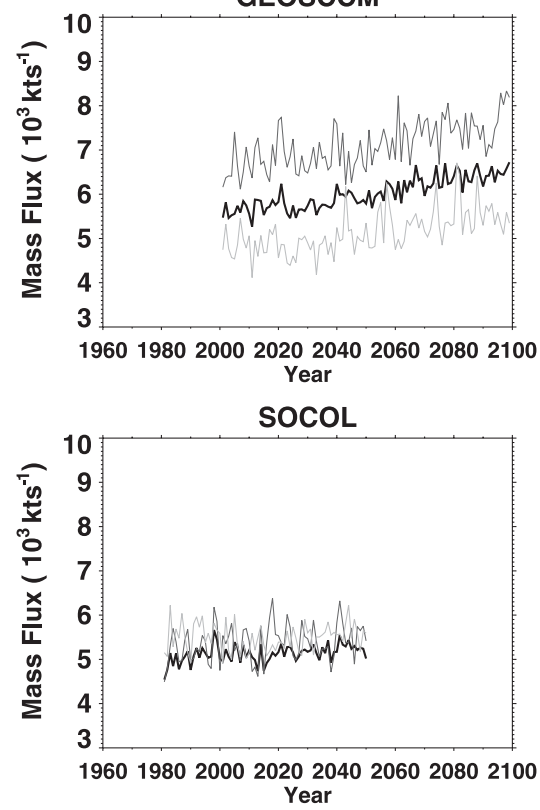

Multi-model mean

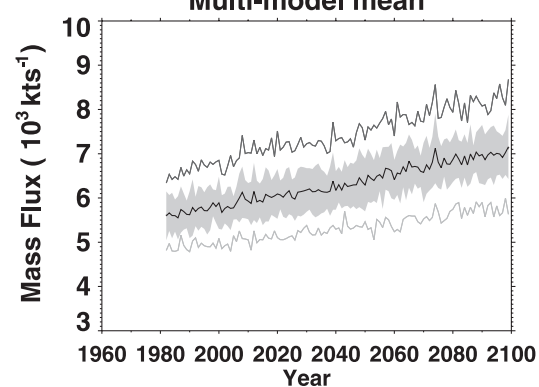

CMAM e

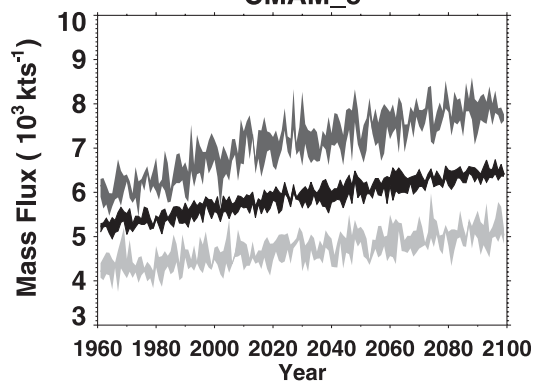

MAECHAM4CHEM

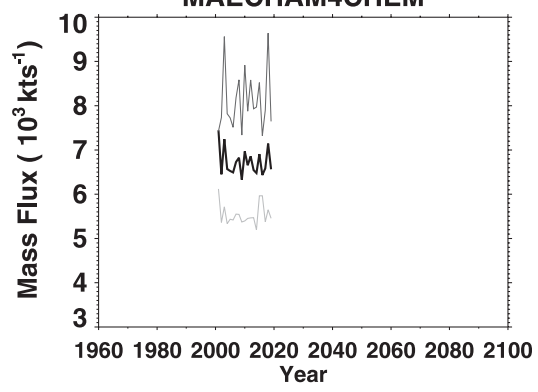

ULAQ

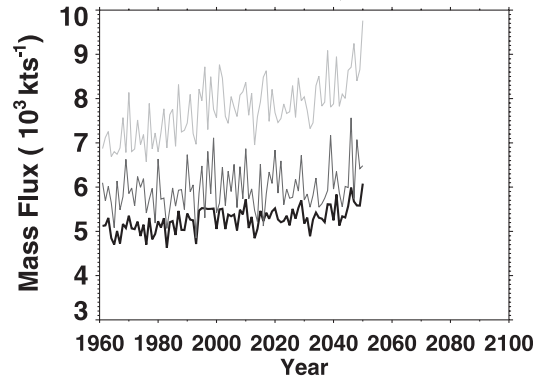

FIG. 7. Time series of the annual (black curves), December-February (dark gray curves), and June-August (light gray curves) mean tropical upwelling mass flux at $70 \mathrm{hPa}(77 \mathrm{hPa}$ for the AMTRAC and $64 \mathrm{hPa}$ for the E39C model) for each model. The upward mass flux is calculated for each season by multiplying the seasonal mean residual vertical velocities [ $\bar{w}^{*}$; see Andrews et al. 1987, their Eq. (3.5.1b)] by a scaling proportional to the cosine of latitude then integrating over all latitudes between $50^{\circ} \mathrm{N}$ and $50^{\circ} \mathrm{S}$, where $\bar{w}^{*}$ is positive (upward). The density at $70 \mathrm{hPa}$ was assumed to be $70 / 1000$ of the mean surface density $\left(1.2 \mathrm{~kg} \mathrm{~m}^{-3}\right)$. The annual mean mass flux is the average of the mass flux calculated for the four seasons, and therefore takes account of the annual cycle in which the upwelling region is displaced from the equator toward the summer hemisphere. The thicker curves used for the AMTRAC, CMAM, E39C, and WACCM results denote the spread between the ensemble members. (Note the mass fluxes were only available for two of the three WACCM simulations.) The short 20-yr simulations (E39C and MAECHAM4CHEM) and also those of the SOCOL and ULAQ models, which were unable to reproduce the correct annual cycle, were excluded from the multimodel mean shown in the bottom middle panel. In this panel the shading denotes \pm two standard error for the annual mean. 
(a) annual mean

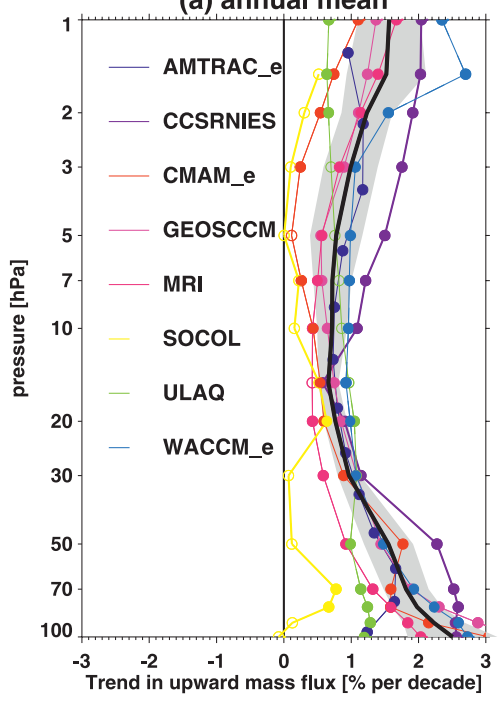

(b) Dec-Jan-Feb mean

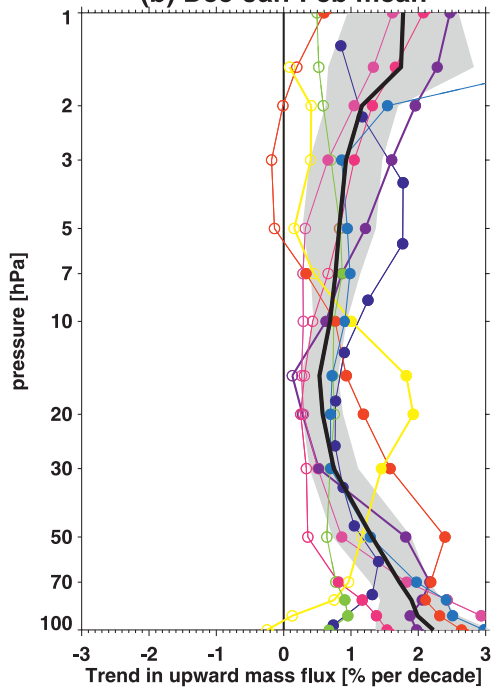

(c) Jun-Jul-Aug mean

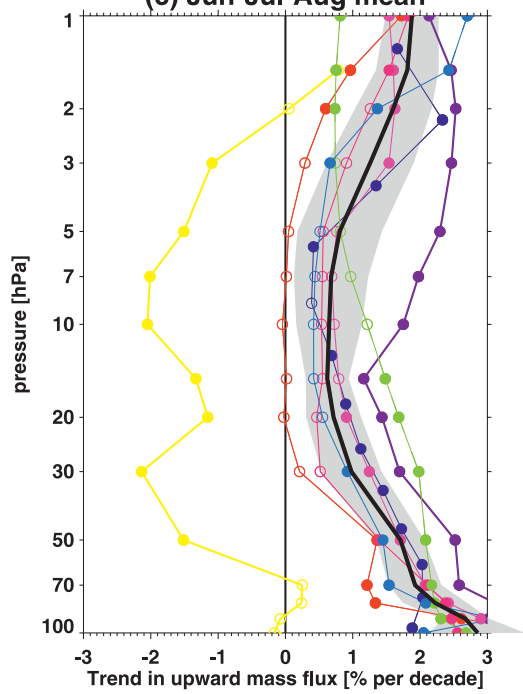

FIG. 8. Vertical profiles of the trends in the tropical upwelling for models with simulations longer than 20 yr for the (a) annual mean, (b) December-February mean, and (c) June-August mean. At each pressure level the upwelling mass flux was calculated using the method described in Fig. 7. The trends were calculated for the entire time series shown in Fig. 7, and for each level they are expressed as a percentage of the upwelling flux obtained from the least squares linear fit for the year 2000. Levels where the trends are statistically significant at the $95 \%$ confidence level are indicated by the filled circles. The black curve is the multimodel mean (excluding the SOCOL and ULAQ models; see the caption for Fig. 7) and the gray shading is the \pm two standard error.

it breaks down in the extratropical lower stratosphere. In this region the mean age of air is determined as much by the horizontal (isentropic) mixing as by the largescale overturning Brewer-Dobson circulation. Therefore, the older-than-average air in the GEOS CCM's extratropical lower stratosphere is probably indicative of weaker mixing in that model compared to the other three models. The low horizontal resolution of the CMAM and the WACCM, and particularly the ULAQ model, likely accounts for the weaker-than-average horizontal age gradients in the low- to midlatitude lower stratosphere in these three models [see also Fig. 10 of Eyring et al. (2006) for the CMAM and WACCM].

In all five models the annual mean of age of air decreases through the twenty-first century everywhere in the middle atmosphere (see Fig. 10), as has been noted for individual models (Austin and Li 2006; Garcia and Randel 2008; Oman et al. 2009). This is consistent with an acceleration of the Brewer-Dobson circulation (see section 4a) and, for the AMTRAC, in agreement with the results of Austin and $\mathrm{Li}$ (2006). Also in all of the models the trends are statistically different from zero at the $95 \%$ confidence level.

Above the lower stratosphere the rates of decrease in age (negative trend) are fairly uniform everywhere. On average, the rate of decrease is much less $(\sim 20 \%)$ in the AMTRAC than in the other models, despite the fact that there is little difference in the rate of increase in tropical upwelling in the AMTRAC compared to the
CMAM, GEOS CCM, or WACCM (see Figs. 7 and 11). The largest rates of decrease in the mean age are, however, seen in the lower stratosphere in the mid- to subtropical latitudes, especially in the WACCM and in the Northern Hemisphere in the GEOS CCM. This suggests that climate change is producing a more rapid transport of air from the tropics to midlatitudes in the lower stratosphere.

While the models all show a decrease of age of air with time, for simulations of both the recent past (not shown) and this century (see also Austin and Li 2006; Garcia and Randel 2008; Oman et al. 2009; Waugh 2009), it is important to note that a recent analysis of a few observations from the Northern Hemisphere midlatitude lower stratosphere $\left(32^{\circ}-51^{\circ} \mathrm{N}\right.$ and $\left.24-35 \mathrm{~km}\right)$ shows a weak increase in estimates of age of air (Engel et al. 2009). However, the large uncertainties in this observational trend estimate mean that the observations are not inconsistent with the model trends (Engel et al. 2009).

\section{c. Wave driving; downward control}

The Brewer-Dobson circulation is a wave-driven circulation (Holton et al. 1995). For steady conditions, the downward control principle of Haynes et al. (1991) allows the residual vertical velocity $\bar{w}^{*}(\phi, z)$ at latitude $\phi$ and $\log$ (pressure)-height $z$ to be expressed in terms of the vertical integral of the mean zonal forces $\overline{\mathcal{F}}$ acting above $z$ as 

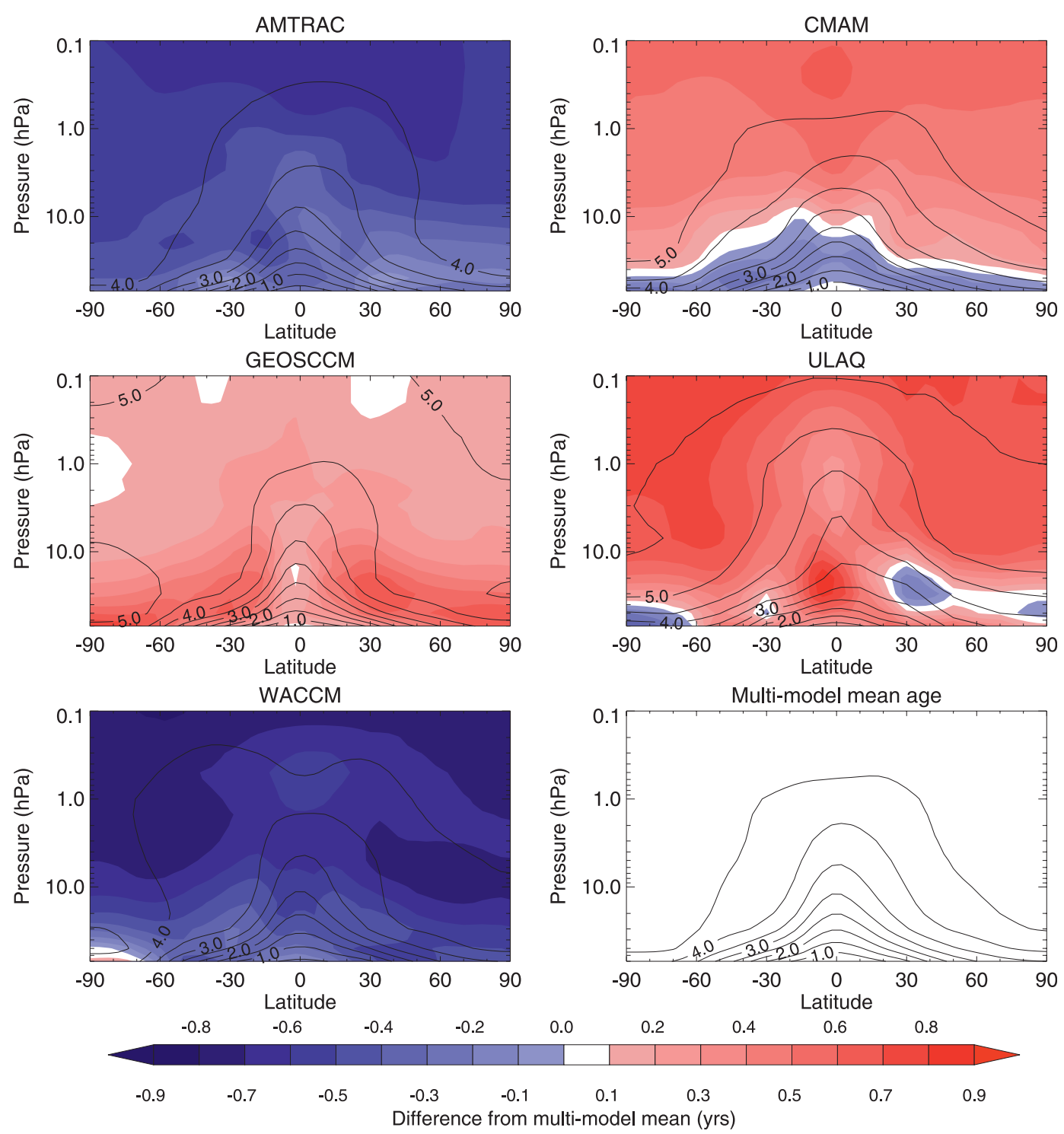

FIG. 9. Annual mean age of air (contours) and the deviation (shading) in years from the (bottom right) multimodel mean for (a) AMTRAC, (b) CMAM, (c) GEOS CCM, (d) the ULAQ model, and (e) WACCM. The results are for the year 2000 based on a linear fit to the full time series of data for each model. When data were available for more than one integration of a particular model the ensemble mean is used. Blue (red) shading denotes air that is younger (older) than the multimodel mean.

$$
\bar{w}^{*}(\phi, z)=-\frac{1}{\rho_{0} \cos \phi} \frac{\partial}{\partial \phi}\left[\int_{z}^{\infty}\left(\frac{\rho_{0} a \overline{\mathcal{F}} \cos ^{2} \phi}{\bar{m}_{\phi}}\right)_{\phi=\phi\left(z^{\prime}\right)} d z^{\prime}\right]
$$

where $\bar{m}=a \cos \phi(\bar{u}+a \Omega \cos \phi)$ is the angular momentum per unit mass, $a$ is the earth's radius, $\Omega$ its angular velocity, $\rho_{0}$ a basic-state density, and $\bar{u}$ the zonal mean eastward wind. The integration is up a line of constant zonal mean absolute angular momentum but breaks down near the equator where the lines are no longer approximately vertical (Haynes et al. 1991). Nonetheless, the total upwelling mass flux in the tropical region can be derived, by continuity, from the sum of the extratropical downwelling mass fluxes in both hemispheres that are calculated using this downward control relationship. For this study all of the downward control integrals are calculated up a line of constant latitude.

In the middle atmosphere the zonal mean forces $\overline{\mathcal{F}}$ are due to Rossby and gravity wave breaking and other dissipative eddy processes. In the models the resolved contribution to the wave breaking is proportional to the 

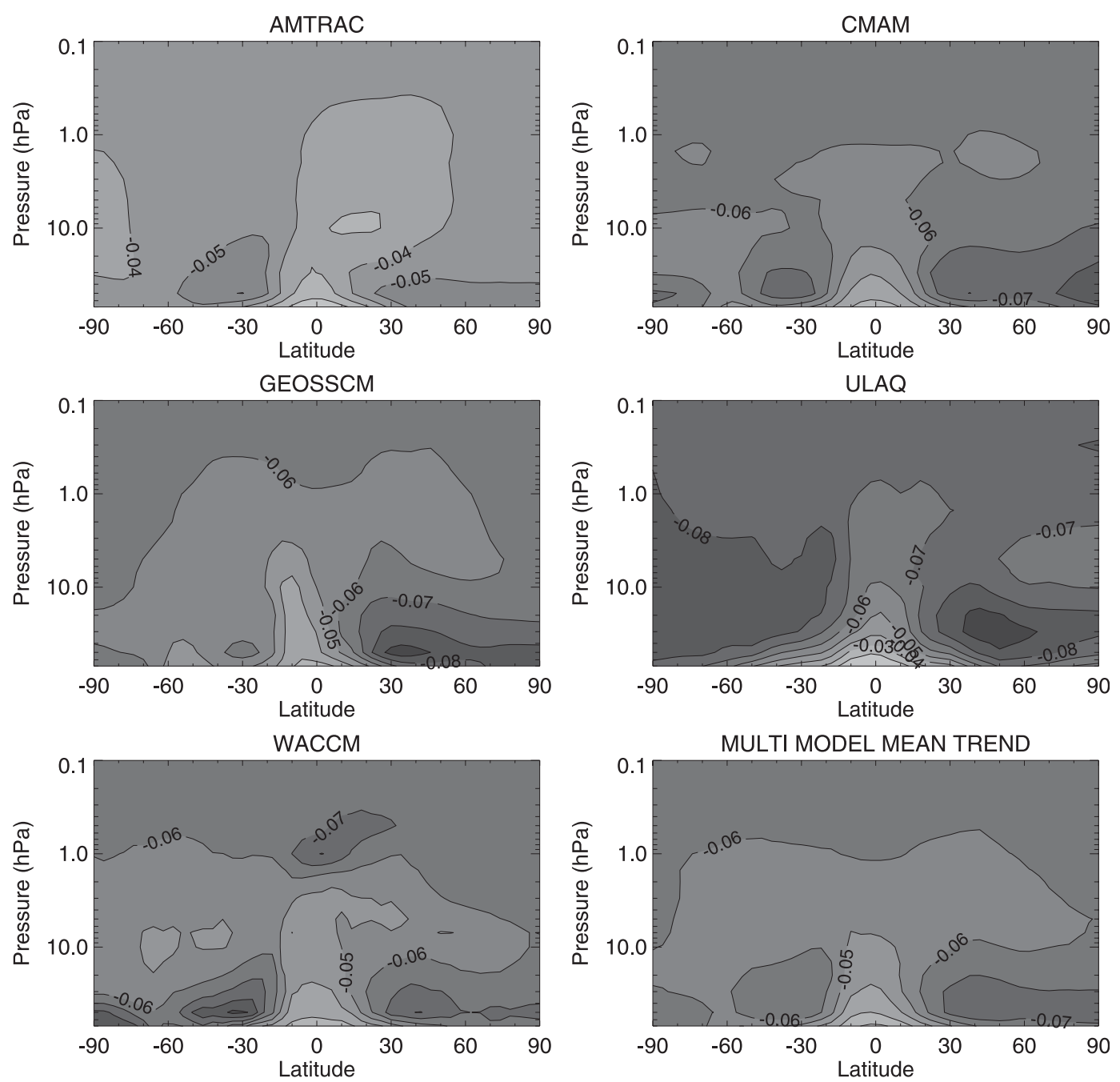

FIG. 10. Trend in the annual mean age of air for the AMTRAC, CMAM, GEOS CCM, ULAQ model, and WACCM ( $\mathrm{yr}_{\text {decade }}{ }^{-1}$ ) along with the (bottom right) multimodel mean trend. When data were available for more than one integration of a particular model, the ensemble mean is used for that model.

divergence of the Eliassen-Palm (EP) flux of wave activity (e.g., chapter 3 in Andrews et al. 1987). The contributions to $\overline{\mathcal{F}}$ from subgrid-scale gravity waves are parameterized with separate schemes for the waves with orographic and nonorographic sources (see section 2 and Table 2 for details). A common feature of all of the parameterizations, however, is the assumption of vertical wave propagation. Consequently, for the parameterized subgrid-scale waves, the downward control integral simply depends on the wave momentum flux at the lower bound of the integral and any flux that is allowed to escape to outer space (Shaw and Shepherd 2007) and does not depend on details of where the momentum is deposited between the upper and lower bounds. In general, the contributions to the downward control integral fall off rapidly with height, and therefore details of the momentum flux escaping to space and also other dissipative processes, such as Rayleigh's friction or diffusion acting near the model's upper boundary, can be neglected when calculating $\bar{w}^{*}$ at $70 \mathrm{hPa}$ from the downward control principle, provided that the model has a sufficiently high upper boundary and momentum conservation is not violated within the stratosphere, for example, by failing to deposit orographic GWD momentum (AMTRAC) or employing Rayleigh friction (ULAQ). All of the models used in this study had an upper boundary above the stratopause apart from the E39C model, which, for simulating the middle atmosphere, had an unusually low upper boundary in the middle stratosphere (see Table 2). Hence, any downward control calculations shown for the E39C model at $70 \mathrm{hPa}$ have to be treated with some caution. Nonetheless, Garny et al. (2009) showed that 

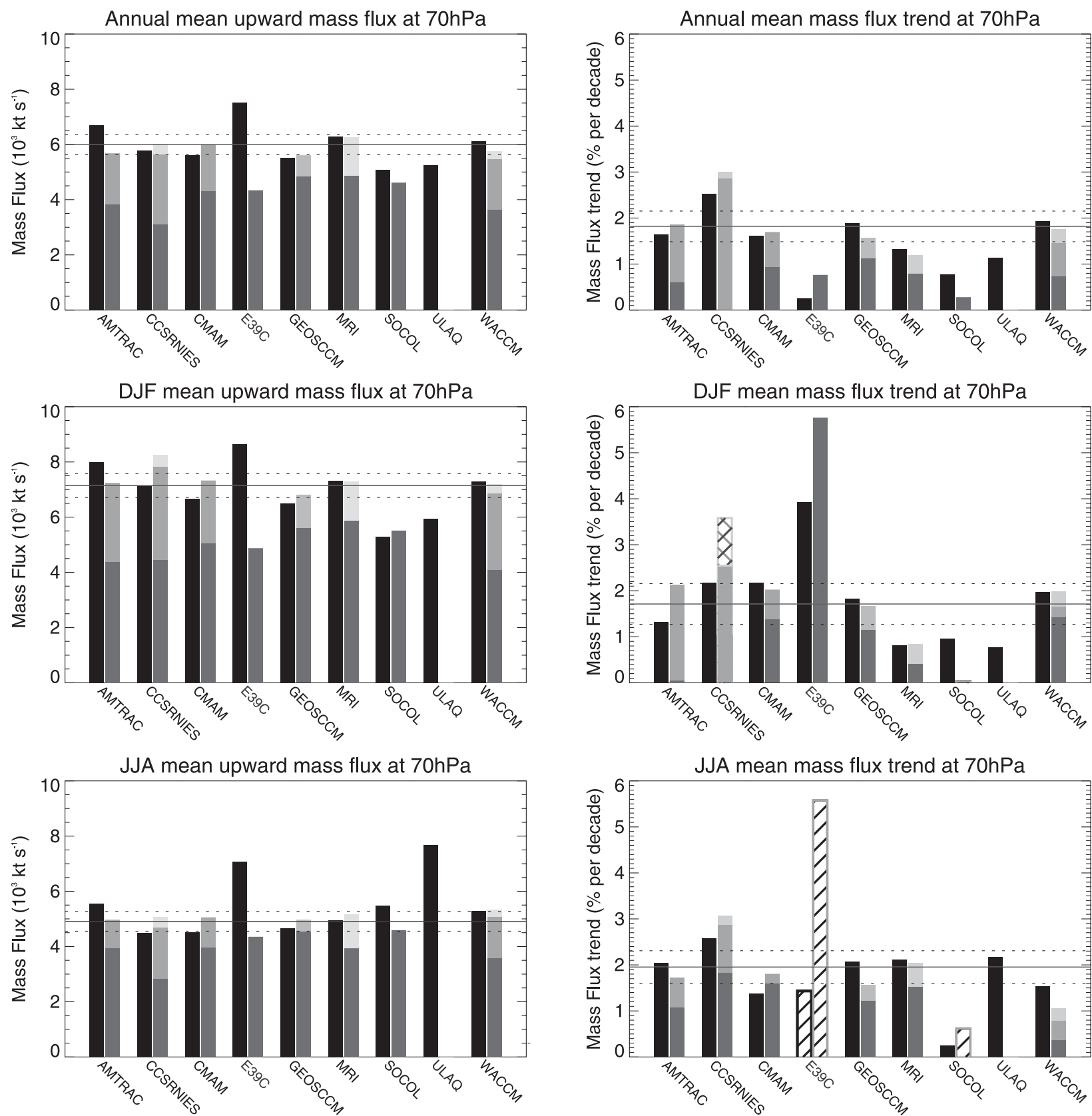

FIG. 11. Comparison of the (top) annual, (middle) December-February, and (bottom) June-August mean tropical upwelling mass fluxes and mass flux trends at $70 \mathrm{hPa}$ (black bars) with those derived from downward control (gray bars). The results are for the total upward mass flux between the turn around latitudes where the residual vertical velocity changes sign from upward to downward. The dark gray shading represents the contribution from the EP flux divergence, with the lighter shadings being the contributions from parameterized orographic and nonorographic gravity waves (lightest shade). The EP flux divergence was not available from ULAQ; GWD was not available for, or not used (see Table 1), in the E39C, SOCOL, and ULAQ models; in addition, nonorographic GWD was unavailable for the AMTRAC. The GWD results shown for the GEOS CCM are the combined orographic and nonorographic contributions. The solid horizontal lines are the multimodel mean with the dashed lines indicating \pm two standard error. When results were available for more than one simulation of a particular model the ensemble mean is used in the figure. The diagonal shading indicated negative trends. (left) Mass fluxes for the year 2000 based on a linear fit to the time series. (right) Trends obtained from the linear fit. 
analysis of the mean tropical upwelling mass fluxes in the low lid model E39C-A at $76 \mathrm{hPa}$ derived directly from the residual velocity and calculated using downward control are qualitatively in good agreement.

Figure 11 shows that, in general, there was reasonably good agreement between the actual tropical upwelling mass fluxes and mass flux trends and those derived from the downward control principle. In most models the orographic gravity waves are of similar importance to the resolved waves (EP flux divergence), both in determining the upwelling and its trend. For the five models (AMTRAC, CCSR/NIES, CMAM, GEOS CCM, and WACCM) for which orographic GWD was available above $70 \mathrm{hPa}$ (for the GEOS CCM the total GWD was used) this accounted for, on average, $30 \%$ of the annual mean tropical upwelling compared to $67 \%$ from the EP flux divergence, though the partitioning varied considerably between the models (from $14 \%$ for the GWD and $88 \%$ from the resolved waves in the GEOS CCM to $44 \%$ and $54 \%$, respectively, in the CCSR/NIES model). In December-February (June-August), the mean contributions from the orographic gravity waves and resolved waves were $35 \%(24 \%)$ and $67 \%(77 \%)$, respectively. The increased contribution from orographic GWD during the boreal winter/austral summer confirms the findings of Li et al. (2008) and McLandress and Shepherd (2009) and establishes that this aspect is robust across a range of models. Unlike the orographic GWD, the nonorographic GWD had very little impact on the downward control-derived mass fluxes in the lower stratosphere (see light gray shading in Fig. 11) because most of the momentum deposited by these waves in the extratropics occurs well above the 70-hPa level (e.g., McLandress and Shepherd 2009).

As first noted by Li et al. (2008) for the AMTRAC simulations, changes in orographic GWD can be a significant contributor to the trends in the upwelling, especially during the boreal winter. The contribution from orographic GWD to the trend in upwelling varied considerably over the five models with GWD diagnostics (AMTRAC, CCSR/NIES, CMAM, GEOS CCM, and WACCM; see right-hand panels in Fig. 11), but on average it accounted for $59 \%$ of the trend in the annual mean upwelling, increasing to $77 \%$ during DecemberFebruary, though this high value is largely due to just two models (the AMTRAC and the CCSR/NIES model). Nonetheless, even the smallest $23 \%$ contribution to the increase in the annual mean upwelling from GWD in the GEOS CCM is large when it is considered that in this model only a modest $14 \%$ of the driving of the upwelling comes from GWD (see left-hand panels in Fig. 11).

Most parameterizations of orographic gravity waves typically deposit momentum in the westward wind shear on the upper side of the subtropical jets, especially in the Northern Hemisphere. This region includes the latitudes where the Brewer-Dobson circulation changes from tropical upwelling to extratropical downwelling, which are the latitudes at which the downward control integrals (see equation above) were calculated to derive the strength of the tropical upwelling shown by the gray bars in Fig. 11. Vertical profiles of the annual mean orographic GWD at these "turn-around latitudes" (i.e., the latitudes where $\bar{w}^{*}=0$ ) are shown for the Northern Hemisphere in Fig. 12a for the AMTRAC, CCSR/NIES, CMAM, GEOS CCM, and WACCM simulations (see the figure legend for details). At the Southern Hemisphere turn-around latitudes the vertical profiles are similar, but the overall orographic GWD is much weaker and is not shown here. In response to climate change in the simulations there was an eastward acceleration of the subtropical jets (see section 3, Fig. 6), which caused the parameterized gravity waves to break higher in the atmosphere resulting in a trend for more drag above $70 \mathrm{hPa}$ and less below as shown in Fig. 12b. In turn, the increased orographic GWD above $70 \mathrm{hPa}$, or more particularly the increased upward gravity wave momentum flux at $70 \mathrm{hPa}$, contributed significantly to the strengthening of the tropical upwelling as indicated by the right-hand panels in Fig. 11. Therefore, in the case of the vertically propagating orographic waves it is the secular changes to the modeled atmospheres below $70 \mathrm{hPa}$ that determined how the GWD affected the response of the tropical upwelling (at $70 \mathrm{hPa}$ ) to climate change, even though that response was the result of "downward control."

It is also worth noting that at those locations where, and/or times when, the parameterized orographic waves are already breaking (i.e., providing drag) below $70 \mathrm{hPa}$ (cf., Fig. 12a for the zonal and time mean) an increase in the upward momentum flux from the surface cannot increase the flux at $70 \mathrm{hPa}$ because the extra flux will just contribute to the momentum deposited at the level at which the waves first break or saturate (only the "unsaturated" flux is allowed to propagate upward in the parameterizations schemes), though a change in the surface flow could change the spatial and temporal extent of the sources. For the CMAM there was only a small change in the momentum flux from the surface (not shown) and the increased drag above $70 \mathrm{hPa}$ in that model came mainly from reduced filtering (breaking) below $70 \mathrm{hPa}$ (McLandress and Shepherd 2009). In the WACCM the flux from the surface was constant and for the other models it was not diagnosed.

In all of the simulations climate change also increased the EP flux entering the stratosphere at $70 \mathrm{hPa}$ in the subtropics (Fig. 13), consistent with an increase in the EP flux divergence above that level accelerating the tropical 

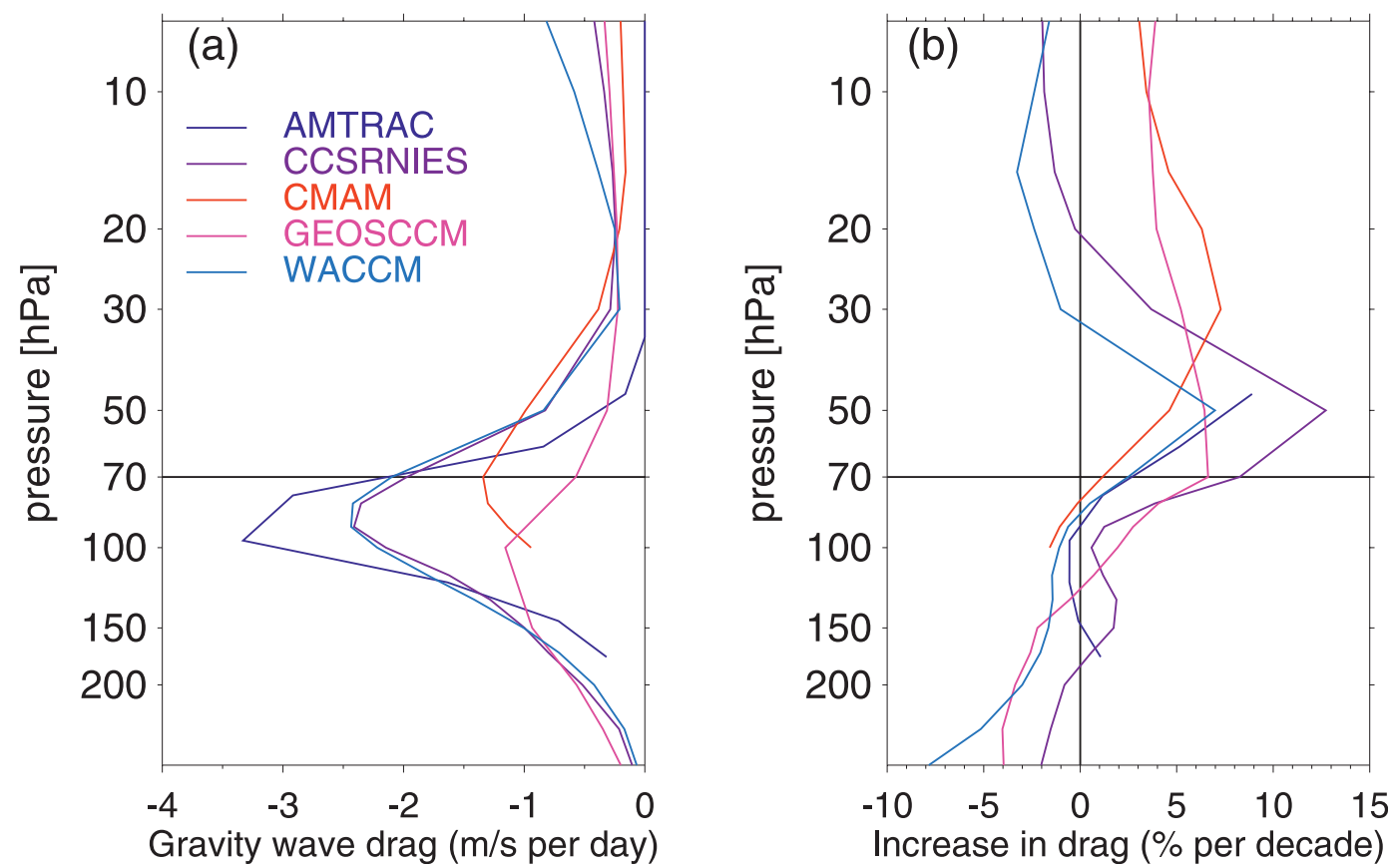

FIG. 12. (a) For the simulations of the AMTRAC, CCSR/NIES model, CMAM, GEOS CCM, and WACCM, the vertical profiles of the annual mean orographic gravity wave drag $\left[\mathrm{m} \mathrm{s}^{-1}\right.$ (day) $\left.{ }^{-1}\right]$ at the latitudes north of the equator, where $\bar{w}^{*}=0$ at $70 \mathrm{hPa}$. The annual mean is the average of the four seasonal means and therefore takes account of the seasonal cycle in the position where $\bar{w}^{*}=0$. The results shown are for the year 2000 based on a linear fit to the time series of annual mean vertical profiles. (b) Change in drag ( $\%$ decade $\left.^{-1}\right)$ based on the linear fit to the time series. When results were available from more than one simulation of a particular model, the ensemble mean is shown. In the AMTRAC orographic gravity wave drag was set to zero above $42 \mathrm{hPa}$. The curves for the AMTRAC and the CMAM do not extend to the lowest levels because data were not provided for those levels. Nonetheless, it should be emphasized that the orographic GWD does operate throughout the depth of the troposphere in these models.

upwelling (e.g., dark gray bars in the right-hand panels of Fig. 11). However, because the resolved waves propagate both horizontally and vertically and can be refracted, it was not possible to quantify the contribution to the downward control integral in terms of just this upward wave momentum flux (i.e., vertical component of the EP flux) at $70 \mathrm{hPa}$, as was done for the parameterized waves. Similarly, the possibility of refraction and the more complex nature of the sources of the resolved waves (Nathan and Cordero 2007), compared to those used for the parameterized waves, make it difficult to identify the causes of the trend in upward wave flux at $70 \mathrm{hPa}$. Nonetheless, a rather detailed analysis of the CMAM by McLandress and Shepherd (2009) showed that the large-scale waves (zonal harmonics 1-3) accounted for about $60 \%$ of the driving of the annual mean upwelling trend by resolved waves, with the remainder coming from synoptic waves (zonal harmonics $>3$ ). This contribution from the synoptic waves increased to around 50\% during December through February. Using additional runs of the GEOS CCM Oman et al. (2009) identified increases in tropical SSTs as a significant contributor to an increase in the resolved wave fluxes, which is consistent with the result of Fomichev et al. (2007) that the associated increase in SSTs adds an additional 1-K cooling, from upwelling, to the cooling of the tropical lower stratosphere from a doubling of $\mathrm{CO}_{2}$. Neither of these studies attempted to separate out the direct contribution resulting from a change in the source of waves from the indirect contribution resulting from a change of propagation due to the tropospheric climate change. Nonetheless, the results of Oman et al. (2009) are consistent with other studies (e.g., Hardiman et al. 2007) that have shown a correlation between variability in tropical SSTs and tropical upwelling at different levels though, critically, Hardiman et al. (2007) noted that the sign of the correlation changes on moving from the troposphere to the stratosphere. Deckert and Dameris (2008) have also reported that higher tropical SSTs can lead to a localized seasonal strengthening of upwelling in the tropics, but it was unclear from the results they show if this would produce a net increase in total upwelling between the turn-around latitudes at $70 \mathrm{hPa}$ as noted in sections $4 \mathrm{a}$ and $4 \mathrm{c}$. 


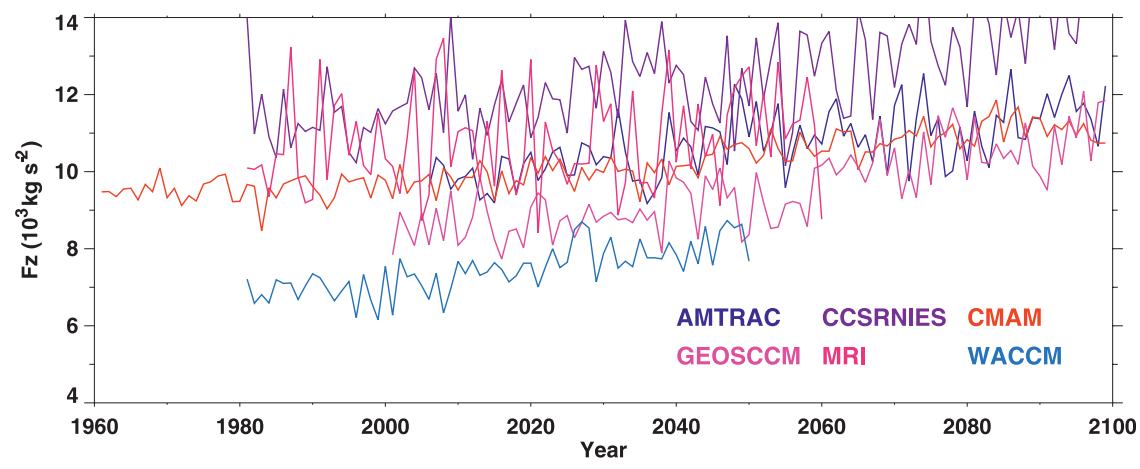

FIG. 13. Time series of the annual mean upward component $\left(F_{z}\right)$ of the EP flux at $70 \mathrm{hPa}$ averaged between $20^{\circ}-40^{\circ} \mathrm{N}$ and $20^{\circ}-40^{\circ} \mathrm{S}$ for the simulations from the AMTRAC, CCSR/NIES model, CMAM, GEOS CCM, MRI model, and WACCM. When result were available from more than one simulation of a particular model the ensemble mean is shown.

\section{Discussion and conclusions}

In this study the response of the stratospheric climate and circulation to increasing amounts of GHGs and ozone recovery in the twenty-first century has been assessed using results from an ensemble of near-identical transient simulations of 11 chemistry-climate models (CCMs). In all of the simulations the abundance of GHGs increased according to the IPCC SRES A1B scenario (Nakicenovic and Swart 2000), while the ozone recovery mainly resulted from a reduction in the amounts of ozone-depleting substances based on the WMO (2003) Ab scenario for halogens, though, in each simulation, the recovery of ozone was modulated by concomitant changes in the modeled climate and circulation (see Eyring et al. 2007). Consequently, a significant difference in the radiative forcing of the climate in the simulations arose from the differences in the model projections of ozone recovery that were reported in Eyring et al. (2007). Another important model-dependent difference in the radiative forcing resulted from the sensitivity of stratospheric water vapor to the modeled tropical tropopause temperatures. In addition, there were differences in the forcing from the prescribed SSTs because of different climate sensitivities in the coupled models used to generate those SSTs, though, again, for each simulation these evolved consistently with the SRES A1B scenario for the GHGs (i.e., they were taken from coupled oceanatmosphere model projections based on the same GHG scenario). All of the simulations included these anthropogenic forcings, while for most of them natural forcings were generally excluded. However simulations from three of the models included a future solar forcing and two models included an artificial QBO forcing in the tropics (see columns 4 and 5 in Table 2). For these models and simulations it was assumed that any nonlinear rectification of this artificially forced natural variability did not contribute directly to the long-term secular changes, and hence the changes or trends reported here represent the stratospheric response to the changes in anthropogenic forcings (i.e., changes in the amounts of GHGs and ODSs).

A rather important component of the "fingerprint" of global climate change is a cooling of the stratosphere, which increases with height. While ozone depletion has been a significant contributor to global mean stratospheric cooling in the past, future stratospheric global temperature changes will be driven overwhelmingly by climate change (Shepherd and Jonsson 2008). All of the simulations assessed in this study produced this fingerprint for the global temperature trend with very little spread between the models or simulations. On average the annual mean cooling at $10 \mathrm{hPa}$ was $0.59 \mathrm{~K} \mathrm{decade}^{-1}$ with the standard error of the ensemble mean of $0.037 \mathrm{~K} \mathrm{decade}^{-1}$. The simulations also suggest additional spatial and temporal structure to the trend, which, in particular, manifests as a warming of the polar lower stratosphere in the austral summer with enhanced cooling above and a near-zero temperature trend in the polar lower stratosphere in the boreal winter. This spatial and temporal structure resulted, however, from a combination of both climate change and ozone recovery.

The warming over Antarctica has been noted before for individual models (e.g., Perlwitz et al. 2008; McLandress and Shepherd 2009) and for IPCC AR4 runs with prescribed ozone changes (Son et al. 2008), though interestingly the signal is not as strong in the AR4 runs as in the chemistry-climate model simulations with their higher upper boundaries (see also Shaw et al. 2009). The results presented in this paper confirm this to be a robust feature of stratospheric change over the next 50 years or so. Moreover, the correlation ( 0.83 for the period of 2000-50) between the rate of recovery of the Antarctic ozone hole (e.g., Eyring et al. 2007) and the strength of 
the polar warming in the simulations implies that the latter is more or less a direct radiative response to ozone recovery, although it is also important to look at the time signature of the changes to confirm the attribution (Hitchcock et al. 2009). At same time it also indicates a sensitivity of the temperature response to details and the accuracy of the interactive ozone chemistry and associated transport of constituents in the models.

Unlike for the Antarctic, there has been little consensus on how the Arctic stratosphere will respond to climate change and ozone recovery (e.g., Austin et al. 2003; WMO 2007, chapter 5). However, the results from the longer simulations assessed here suggest that the extra radiative cooling from growing amounts of GHGs will be approximately balanced by a concomitant increase in the adiabatic warming through increased polar downwelling. The net effect is a near-zero temperature trend in the Arctic winter lower stratosphere. Because this signal of climate change is the small residual of much larger, but similarly sized, perturbations to the adiabatic warming and diabatic cooling, it is not statistically significant in a single simulation with respect to the large natural interannual variability in this region. Nonetheless, the results from the multimodel ensemble confirm that the signal is probably a robust feature of climate change.

An important consequence of the long-term stratospheric temperature changes in the polar latitudes is the effect on the occurrence of PSCs, and hence ozone loss in these regions. In this study trends in the occurrences of PSCs inferred from the modeled daily temperature fields generally agreed well with the trends obtained directly from the parameterizations of PSC processes within the models. A fairly robust feature in the Antarctic was a steep increase in the accumulated area of PSCs in response to the development of the ozone hole, with most of this increase consequently coming in late spring (Hitchcock et al. 2009), followed by a gentle increase in the future as cooling from climate change dominates the warming from ozone recovery. Because the climate change-induced changes in PSC occurrence occur throughout the winter (Hitchcock et al. 2009), this means that even as the ODSs begin to disappear from the stratosphere the areal extent of the ozone hole could still expand further before it disappears. In the Arctic there was much greater spread between the models, but consistently with the near-zero seasonal mean temperature trends in this region (see above), the models suggest that on average there would be no significant change in occurrences of PSCs in the near future and throughout the twenty-first century.

Another important consequence of the temperature trends was a change in the temperature gradients and thus, through thermal wind balance, a change in the zonal mean eastward wind. Results from the multimodel comparison indicate two robust features. First, there was an eastward acceleration of the subtropical jet in both hemispheres, which had important ramifications for both the parameterized gravity waves and also the resolved (Rossby) waves propagating into the stratosphere (see below). Second, there was a westward acceleration of the lower-stratospheric winds over Antarctica during December-February, which corresponds to a decrease in the amplitude of the southern annular mode. Like the temperatures in this region this response was sensitive to the strength of the ozone recovery in the models and was not present in those twenty-first century IPCC AR4 simulations that did not include the ozone recovery or had a poor representation of the stratosphere (Perlwitz et al. 2008; Son et al. 2008). This is particularly significant because there is evidence (Perlwitz et al. 2008; Son et al. 2008) that indicates the signal in the stratospheric winds can extend to the surface where there are possible interesting implications for the carbon uptake by the Southern Ocean (e.g., Matear and Lenton 2008).

In all of the models the annual mean tropical upwelling at $70 \mathrm{hPa}$ was predicted to increase by, on average, $\sim 2 \%$ decade $^{-1}$, confirming the earlier results of Butchart et al. (2006). The results of this study also established that the predicted increase occurred throughout the depth of the stratosphere and caused a fairly uniform reduction in the age of air of roughly $0.05 \mathrm{yr}$ decade $^{-1}$ in those models for which this diagnostic was available. Moreover, the differences between the mean age in these models correlated well with respective differences in the tropical upwelling (i.e., models with a faster-than-average Brewer-Dobson circulation had younger-than-average air and vice versa), apart from in the extratropical lower stratosphere where horizontal mixing is as important as the large-scale overturning circulation. This suggests that the spread in the simulated age can be attributed mostly to a corresponding spread in the strength of the Brewer-Dobson circulation and not directly to the differences in the tracer advection schemes. On the other hand, the differences in the advection schemes could contribute to the differences in horizontal mixing.

In those models for which the information was available $30 \%$ of the driving and $59 \%$ of the trend in the annual mean tropical upwelling in the lower stratosphere was, on average, due to the parameterized orographic gravity waves. The importance of the orographic as opposed to nonorographic gravity waves was a common feature of all the models that provided these diagnostics. While it should be noted that the momentum fluxes in the lower stratosphere resulting from orographic gravity waves are not well constrained by observations, the basic 
mechanism of orographic gravity wave breaking heights shifting upward as the zonal winds strengthen is based on fundamental fluid dynamical principles. With the formulations used, the trend in upwelling resulting from the orographic waves is a direct consequence of the eastward acceleration of the subtropical jets in response to climate change (see above) allowing more waves to propagate and break above $70 \mathrm{hPa}$.

The overall conclusion of this analysis is that there are several robust features that all (or nearly all) models predict, that is, consistent trends in temperature, PSC occurrence, zonal winds, tropical upwelling, age of air, and the processes driving the Brewer-Dobson circulation. Further improvement of the models, including their representation of tropospheric climate change, should lead to a refinement of these predictions. However, the trends in some quantities (e.g., lower-stratosphere south polar temperatures) are sensitive to the projected rate of ozone recovery in the models, which depends on the extent of their simulated ozone depletion. Hence, improving the predictions of these quantities will depend on improving the simulation of ozone depletion and recovery and will require the additional consideration of the chemistry and transport characteristics of the models, which is quite beyond the scope of this study. Furthermore, to properly assess the impact of the changes in the stratosphere on the surface climate will require simulations with a fully interactive ocean.

Acknowledgments. The authors acknowledge the Chemistry-Climate Model Validation Activity (CCMVal) of the WCRP's (World Climate Research Programme) SPARC (Stratospheric Processes and their Role in Climate) project for organizing and coordinating the model data analysis activity, and the British Atmospheric Data Centre (BADC) for collecting and archiving the CCMVal model output. The European groups acknowledge support of the EC Integrated Project SCOUT-O3 (505390GOCE-CT-2004) funded by the European Commission. Dr. Butchart's research was supported by the Joint DECC, Defra, and MoD Integrated Climate ProgrammeDECC/Defra (GA01101), MoD (CBC/2B/0417_Annex C5), and SCOUT-O3. CCSR/NIES research was supported by the Global Environmental Research Fund (GERF) of the Ministry of the Environment (MOE) of Japan (A-071). The CMAM research was supported by the Canadian Foundation for Climate and Atmospheric Sciences through the C-SPARC project. GEOS CCM simulations were conducted on NASA's High-Performance computing resources at NASA Ames Research Center. The MRI simulation was made with the supercomputer at the National Institute for Environmental Studies, Japan.

\section{REFERENCES}

Akiyoshi, H., and Coauthors, 2009: A CCM simulation of the breakup of the Antarctic polar vortex in the years 1980-2004 under the CCMVal scenarios. J. Geophys. Res., 114, D03103, doi:10.1029/2007JD009261.

Alexander, M. J., and T. J. Dunkerton, 1999: A spectral parameterization of mean-flow forcing due to breaking gravity waves. J. Atmos. Sci., 56, 4167-4182.

Andrews, D. G., J. R. Holton, and C. B. Leovy, 1987: Middle Atmosphere Dynamics. International Geophysical Series, Vol. 40, Academic Press, 489 pp.

Austin, J., and F. Li, 2006: On the relationship between the strength of the Brewer-Dobson circulation and the age of stratospheric air. Geophys. Res. Lett., 33, L17807, doi:10.1029/2006GL026867.

_ and recovery of stratospheric ozone. J. Geophys. Res., 111, D16314, doi:10.1029/2005JD006907.

_ _ and Coauthors, 2003: Uncertainties and assessments of chemistry-climate models of the stratosphere. Atmos. Chem. Phys., 3, 1-27.

_ - R. J. Wilson, F. Li, and H. Vömel, 2007: Evolution of water vapor concentrations and stratospheric age of air in coupled chemistry-climate model simulations. J. Atmos. Sci., 64, 905-921.

— simulations of stratospheric temperatures and their trends for the recent past. Geophys. Res. Lett., 36, L13809, doi:10.1029/ 2009GL038462.

Baldwin, M. P., M. Dameris, and T. G. Shepherd, 2007: How will the stratosphere affect climate change? Science, 316, 15761577.

Beagley, S. R., J. de Grandpré, J. N. Koshyk, N. A. McFarlane, and T. G. Shepherd, 1997: Radiative-dynamical climatology of the first-generation Canadian Middle Atmosphere Model. Atmos.Ocean, 35, 293-331.

Butchart, N., and A. A. Scaife, 2001: Removal of chlorofluorocarbons by increased mass exchange between the stratosphere and troposphere in a changing climate. Nature, 410, 799-802.

_, J. Austin, J. R. Knight, A. A. Scaife, and M. L. Gallani, 2000: The response of the stratospheric climate to projected changes in the concentrations of well-mixed greenhouse gases from 1992 to 2051. J. Climate, 13, 2142-2159.

_ - and Coauthors, 2006: Simulations of anthropogenic change in the strength of the Brewer-Dobson circulation. Climate Dyn., 27, 727-741.

Carslaw, K. S., B. P. Luo, and T. Peter, 1995: An analytic expression for the composition of aqueous $\mathrm{HNO}_{3}-\mathrm{H}_{2} \mathrm{SO}_{4}$ stratospheric aerosols including gas phase removal coupled $\mathrm{HNO}_{3}$. Geophys. Res. Lett., 22, 1877-1880.

Considine, D. B., A. R. Douglass, P. S. Connell, D. E. Kinnison, and D. A. Rotman, 2000: A polar stratospheric cloud parameterization for the global modeling initiative three-dimensional model and its response to stratospheric aircraft. J. Geophys. Res., 105, 3955-3974.

Cordero, E., and P. M. de F. Forster, 2006: Stratospheric variability and trends in models used for the IPCC AR4. Atmos. Chem. Phys., 6, 5369-5380.

Dameris, M., and Coauthors, 2005: Long-term changes and variability in a transient simulation with a chemistry-climate model employing realistic forcings. Atmos. Chem. Phys., 5, 2121-2145. , S. Matthes, R. Deckert, V. Grewe, and M. Ponater, 2006: Solar cycle effect delays onset of ozone recovery. Geophys. Res. Lett., 33, L03806, doi:10.1029/2005GL024741. 
Deckert, R., and M. Dameris, 2008: Higher tropical SSTs strengthen the tropical upwelling via deep convection. Geophys. Res. Lett., 35, L10813, doi:10.1029/2008GL033719.

de Grandpré, J., S. R. Beagley, V. I. Fomichev, E. Griffioen, J. C. McConnell, A. S. Medvedev, and T. G. Shepherd, 2000: Ozone climatology using interactive chemistry: Results from the Canadian Middle Atmosphere Model. J. Geophys. Res., 105, 26 475-26 492.

Egorova, T., E. Rozanov, V. Zubov, E. Manzini, W. Schmutz, and T. Peter, 2005: Chemistry-climate model SOCOL: A validation of the present-day climatology. Atmos. Chem. Phys., 5, 1557-1576.

Engel, A., and Coauthors, 2009: Age of stratospheric air unchanged within uncertainties over the past 30 years. Nat. Geosci., 2, 28-31.

Eyring, V., D. E. Kinnison, and T. G. Shepherd, 2005: Overview of planned couple chemistry-climate simulations to support upcoming ozone and climate assessments. SPARC Newsletter, No. 25, Stratospheric Processes and their Role in Climate IPO, Toronto, ON, Canada, 11-17.

— - and Coauthors, 2006: Assessment of temperature, trace spices, and ozone in chemistry-climate model simulations of the recent past. J. Geophys. Res., 111, D22308, doi:10.1029/ 2006JD007327.

- - and Coauthors, 2007: Multi-model projections of ozone recovery in the 21st century. J. Geophys. Res., 112, D16303, doi:10.1029/2006JD008332.

Fomichev, V. I., A. I. Jonsson, J. de Grandpré, S. R. Beagley, C. McLandress, K. Semeniuk, and T. G. Shepherd, 2007: Response of the middle atmosphere to $\mathrm{CO}_{2}$ doubling: Results from the Canadian Middle Atmosphere Model. J. Climate, 20, $1121-1144$.

Garcia, R. R., and S. Solomon, 1985: The effect of breaking gravity waves on the dynamics and chemical composition of the mesosphere and lower thermosphere. J. Geophys. Res., 90, 38503868.

— circulation due to increases in greenhouse gases. J. Atmos. Sci., 65, 2731-2739.

_ D. R. Marsh, D. E. Kinnison, B. A. Boville, and F. Sassi, 2007: Simulations of secular trends in the middle atmosphere, 1950-2003. J. Geophys. Res., 112, D09301, doi:10.1029/ 2006JD007485.

Garny, H., M. Dameris, and A. Stenke, 2009: Impact of prescribed SSTs on climatologies and long-term trends in CCM simulations. Atmos. Chem. Phys. Discuss., 9, 4489-4524.

Giorgetta, M. A., and L. Bengtsson, 1999: The potential role of the quasi-biennial oscillation in the stratosphere-troposphere exchange as found in water vapor in general circulation model experiments. J. Geophys. Res., 104, 6003-6020.

Hanson, D., and K. Mauersberger, 1988: Laboratory studies of the nitric acid trihydrate: Implications for the south polar stratosphere. Geophys. Res. Lett., 15, 855-858.

Hardiman, S. C., N. Butchart, P. H. Haynes, and S. H. E. Hare, 2007: A note on forced versus internal variability of the stratosphere. Geophys. Res. Lett., 34, L12803, doi:10.1029/ 2007GL029726.

Haynes, P. H., M. E. McIntyre, T. G. Shepherd, C. J. Marks, and K. P. Shine, 1991: On the "downward control" of the extratropical diabatic circulations by eddy-induced mean zonal forces. J. Atmos. Sci., 48, 651-678.

Hines, C. O., 1997: Doppler-spread parameterization of gravity wave momentum deposition in the middle atmosphere. Part 2
Broad and quasi monochromatic spectra, and implementation. J. Atmos. Sol.-Terr. Phys., 59, 387-400.

Hitchcock, P., T. G. Shepherd, and C. McLandress, 2009: Past and future conditions for polar stratospheric cloud formation simulated by the Canadian Middle Atmosphere Model. Atmos. Chem. Phys., 9, 483-495.

Holton, J. R., 1982: The role of gravity wave induced drag and diffusion in the momentum budget of the mesosphere. J. Atmos. Sci., 39, 791-799.

— , P. H. Haynes, M. E. McIntyre, A. R. Douglas, R. B. Rood, and L. Pfister, 1995: Stratosphere-troposphere exchange. Rev. Geophys., 33, 403-439.

Johns, T. C., and Coauthors, 2006: The new Hadley Centre climate model HadGEM1: Evaluation of coupled simulations. J. Climate, 19, 1327-1353.

Jonsson, A. I., J. de Grandpré, V. I. Fomichev, J. C. McConnell, and S. R. Beagley, 2004: Doubled $\mathrm{CO}_{2}$-induced cooling in the middle atmosphere: Photochemical analysis of the ozone radiative feedback. J. Geophys. Res., 109, D24103, doi:10.1029/ 2004JD005093.

Kiehl, J. T., B. A. Boville, and B. P. Briegleb, 1988: Response of a general circulation model to a prescribed Antarctic ozone hole. Nature, 332, 501-504.

Kurokawa, J., H. Akiyoshi, T. Nagashima, H. Masunaga, M. Takahashi, and H. Nakane, 2005: Effects of atmospheric sphericity on stratospheric chemistry and dynamics over Antarctica. J. Geophys. Res., 110, D21305, doi:10.1029/ 2005JD005798.

Li, F., J. Austin, and J. Wilson, 2008: The strength of the BrewerDobson circulation in a changing climate: A coupled chemistryclimate model simulation. J. Climate, 21, 40-57.

Lindzen, R. S., 1981: Turbulence and stress owing to gravity wave and tidal breakdown. J. Geophys. Res., 86, 9707-9714.

Mahlman, J. D., L. J. Umscheid, and J. P. Pinto, 1994: Transport, radiative, and dynamical effects of the Antarctic ozone hole: A GFDL "SKYHI" model experiment. J. Atmos. Sci., 51, 489-508.

Manney, G. L., J. L. Sabutis, S. Pawson, M. L. Santee, B. Naujokat, R. Swinbank, M. E. Gelman, and W. Ebisuzaki, 2003: Lower stratospheric temperature differences between meteorological analyses in two cold Arctic winters and their impact on polar processing studies. J. Geophys. Res., 108, 8328, doi:10.1029/ 2001JD001149.

— , and Coauthors, 2005: Diagnostic comparison of meteorological analyses during the 2002 Antarctic winter. Mon. Wea. Rev., 133, 1261-1278.

Manzini, E., B. Steil, C. Brühl, M. A. Giorgetta, and K. Krüger, 2003: A new interactive chemistry-climate model: 2. Sensitivity of the middle atmosphere to ozone depletion and increase in greenhouse gases and implications for recent stratospheric cooling. J. Geophys. Res., 108, 4429, doi:10.1029/ 2002JD002977.

Matear, R. J., and A. Lenton, 2008: Impact of historical climate change on the Southern Ocean carbon cycle. J. Climate, 21, $5820-5834$

McLandress, C., and T. G. Shepherd, 2009: Simulated anthropogenic changes in the Brewer-Dobson circulation, including its extension to high latitudes. J. Climate, 22, 1516-1540.

Nakicenovic, N., and R. Swart, Eds., 2000: Special Report on Emissions Scenarios. Cambridge University Press, 570 pp.

Nathan, T. R., and E. C. Cordero, 2007: An ozone-modified refractive index for vertically propagating planetary waves. J. Geophys. Res., 112, D02105, doi:10.1029/2006JD007357. 
Oman, L., D. W. Waugh, S. Pawson, R. S. Stolarski, and P. A. Newman, 2009: On the influence of anthropogenic forcings on changes in the stratospheric mean age. J. Geophys. Res., 114, D03105, doi:10.1029/2008JD010378.

Pawson, S., K. Krüger, R. Swinbank, M. Bailey, and A. O’Neill, 1999: Intercomparison of two stratospheric analyses: Temperatures relevant to polar stratospheric cloud formation. J. Geophys. Res., 104, 2041-2050.

— , R. S. Stolarski, A. R. Douglass, P. A. Newman, J. E. Nielsen, S. M. Frith, and M. L. Gupta, 2008: Goddard Earth Observing System chemistry-climate model simulations of stratospheric ozone-temperature coupling between 1950 and 2005. J. Geophys. Res., 113, D12103, doi:10.1029/2007JD009511.

Perlwitz, J., and N. Harnik, 2003: Observational evidence of a stratospheric influence on the troposphere by planetary wave reflection. J. Climate, 16, 3011-3026.

— S. Sawson, R. L. Fogt, J. E. Nielsen, and W. D. Neff, 2008: Impact of stratospheric ozone hole recovery on Antarctic climate. Geophys. Res. Lett., 35, L08714, doi:10.1029/2008GL033317.

Pitari, G., E. Mancini, V. Rizi, and D. Shindell, 2002: Feedback of future climate and sulfur emission changes on stratospheric aerosols and ozone. J. Atmos. Sci., 59, 414-440.

Rex, M., and Coauthors, 2006: Arctic winter 2005: Implications for stratospheric ozone loss and climate change. Geophys. Res. Lett., 33, L23808, doi:10.1029/2006GL026731.

Rozanov, E., and Coauthors, 2005: Assessment of the ozone and temperature variability during 1979-1993 with the chemistryclimate model SOCOL. Adv. Space Res., 35, 1375-1384.

Santer, B. D., and Coauthors, 2008: Consistency of modelled and observed temperature trend in the tropical troposphere. Int. J. Climatol., 28, 1703-1722.

Scaife, A. A., N. Butchart, C. D. Warner, and R. Swinbank, 2002: Impact of a spectral gravity wave parameterization on the stratosphere in the Met Office Unified Model. J. Atmos. Sci., 59, 1473-1489.

_ , J. R. Knight, G. K. Vallis, and C. K. Folland, 2005: A stratospheric influence on the winter NAO and North Atlantic surface climate. Geophys. Res. Lett., 32, L18715, doi:10.1029/ 2005 GL023226.

Scinocca, J. F., 2003: An accurate spectral nonorographic gravity wave parameterization for general circulation models. $J$. Atmos. Sci., 20, 667-682.

_ N. A. McFarlane, M. Lazare, J. Li, and D. Plummer, 2008: The CCCma third generation AGCM and its extension into the middle atmosphere. Atmos. Chem. Phys., 8, 7055-7074.

Shaw, T. A., and T. G. Shepherd, 2007: Angular momentum conservation and gravity wave drag parameterization: Implications for climate models. J. Atmos. Sci., 64, 190-203.

-, M. Sigmond, T. G. Shepherd, and J. F. Scinocca, 2009: Sensitivity of simulated climate to conservation of momentum in gravity wave drag parameterization. J. Climate, 22, 27262742 .
Shepherd, T. G., and A. I. Jonsson, 2008: On the attribution of stratospheric ozone and temperature changes to changes in ozone-depleting substances and well-mixed greenhouse gases. Atmos. Chem. Phys., 8, 1435-1444.

Shibata, K., and M. Deushi, 2005: Partitioning between resolved wave forcing and unresolved gravity wave forcing to the quasibiennial oscillation as revealed with a coupled chemistryclimate model. Geophys. Res. Lett., 32, L12820, doi:10.1029/ 2005/GL022885.

,,-- T. T. Sekiyama, and H. Yoshimura, 2005: Development of the MRI chemical transport model for the study of stratospheric chemistry. Pap. Meteor. Geophys., 55, 75-119.

Shiogama, H., M. Watanabe, M. Kimoto, and T. Nozawa, 2005: Anthropogenic and natural forcing impacts on ENSO-like decadal variability during the second half of the 20th century. Geophys. Res. Lett., 32, L21714, doi:10.1029/2005GL023871.

Smith, A. K., and L. V. Lyjak, 1985: An observational estimate of gravity wave drag from the momentum balance in the middle atmosphere. J. Geophys. Res., 90, 2233-2241.

Son, S.-W., and Coauthors, 2008: Impact of stratospheric ozone recovery on the Southern Hemisphere westerly jet. Science, 320, 1486-1489.

Steil, B., C. Brühl, E. Manzini, P. J. Crutzen, J. Lelieveld, P. J. Rasch, E. Roeckner, and K. Krüger, 2003: A new interactive chemistry-climate model: 1 . Present-day climatology and interannual variability of the middle atmosphere using the model and 9 years of HALOE/UARS data. J. Geophys. Res., 108, 4290, doi:10.1029/2002JD002971.

Taylor, K. E., D. Williamson, and F. Zwiers, 2000: The sea surface temperature and sea-ice concentration boundary conditions for AMIP II simulations. Lawrence Livermore National Laboratory PCMDI Rep. 60, 28 pp. [Available online at http:// www-pcmdi.llnl.gov/publications/pdf/60.pdf.]

Tian, W., and M. P. Chipperfield, 2005: A new coupled chemistryclimate model for the stratosphere: The importance of coupling for future $\mathrm{O}_{3}$-climate predictions. Quart. J. Roy. Meteor. Soc., 131, 281-304.

Warner, C. D., and M. E. McIntyre, 1996: On the propagation and dissipation of gravity wave spectra through a realistic middle atmosphere. J. Atmos. Sci., 53, 3213-3235.

Waugh, D. W., 2009: Atmospheric dynamics: The age of stratospheric air. Nat. Geosci., 2, 14-16.

WMO, 2003: Scientific assessment of ozone depletion: 2002. World Meteorological Organization Global Ozone Research and Monitoring Project Rep. 47, 498 pp.

, 2007: Scientific assessment of ozone depletion: 2006. World Meteorological Organization Global Ozone Research and Monitoring Project Rep. 50, 572 pp.

Yukimoto, S., A. Noda, T. Uchiyama, S. Kusunoki, and A. Kitoh, 2005: Climate changes of the twentieth through twenty-first centuries simulated by the MRI-CGCM2.3. Pap. Meteor. Geophys., 56, 9-24. 